\title{
LA OBJECIÓN DE CONCIENCIA EN EL ÁMBITO SANITARIO
}

DAVID ORTEGA GUTIÉRREZ

Prof. Dr. Derecho Constitucional

C.U. Francisco de Vitoria 


\section{SUMARIO}

I. IntRoducción. Regulación parcial de LA objeción de conciencia en la ConstituCIÓN DE 1978. II. ELEMENTOS CONSTITUTIVOS DE LA OBJECIÓN DE CONCIENCIA. III. SUJETOS DE LA OBJECIÓN DE CONCIENCIA. IV. DiFERENTES SUPUESTOS DE LA OBJECIÓN DE CONCIENCIA: 1. La objeción de conciencia del personal sanitario. a) Introducción; b) Sujetos; c) Perspectiva profesional; d) Regulación jurídica; e) Límites; f) Procedimiento y actividades objetables y; g) Consecuencias del ejercicio de la objeción. 2. La objeción de conciencia del paciente y la asistencia médica obligatoria o coactiva. a) Los Testigos de Jehová; b) Los presos y la huelga de hambre. 3. La objeción de conciencia farmacéutica. a) Cuestiones previas; b) Diferentes supuestos. 


\title{
'LA OBJECIÓN DE CONCIENCIA EN EL ÁMBITO SANITARIO'
}

POR

\author{
DAVID ORTEGA GUTIÉRREZ \\ Prof. Dr. Derecho Constitucional \\ C.U. Francisco de Vitoria
}

\section{INTRODUCCIÓN. REGULACIÓN PARCIAL DE LA OBJECIÓN DE CONCIENCIA EN LA CONSTITUCIÓN DE 1978}

Aunque la objeción de conciencia sea un derecho relativamente reciente, la idea de objeción de conciencia la podemos encontrar ya en el siglo $v$ a.C. Sófocles, en su Antígona, plantea esta cuestión. El rey Creonte decreta no enterrar los cadáveres del enemigo. Antígona, hermana de uno de los fallecidos -Polinices-, infringe esta norma. En el primer encuentro entre ambos, se da el siguiente diálogo:

CREONTE "pero tú (a Antigona) dime brevemente, sin extenderte; ¿sabias que estaba decretado no hacer esto?

ANTíGONA Sí, lo sabía: ¿cómo no iba a saberlo? Todo el mundo lo sabe.

CREONTE Y, así y todo, ¿te atreviste a pasar por encima de la ley?

ANTÍGONA No era Zeus quien me la había decretado, ni Dike, compañera de los dioses subterráneos, perfiló nunca

1 Deseo agradecer al profesor Federico Montalvo Jääskeläinen sus siempre interesantes aportaciones en esta materia, tan trabajada por él, del Derecho sanitario. 
entre los hombres leyes de este tipo. Y no creía yo que tus decretos tuvieran tanta fuerza como para permitir que sólo un hombre pueda saltar por encima de las leyes no escritas, inmutables, de los dioses: su vigencia no es de hoy ni de ayer, sino de siempre»².

Sin embargo, el primer testimonio real de objeción de conciencia que ha pasado a la eternidad -parafraseando el título de la película de Fred Zinnemann sobre Tomás Moro $^{3}$ - es la vida 0 , más preciso, la muerte de Moro, Santo Tomás Moro. En su obra, Un hombre solo: Cartas desde la Torre ${ }^{4}$, encontramos el mejor testimonio de las razones y creencias que movieron a Moro a ser fiel a sus principios e ideas hasta las últimas consecuencias. La mayor parte de la correspondencia, la constituyen las cartas entre Moro y su amada hija Margaret que, al igual que Critón con Sócrates, busca. persuadir a su padre para que abandone su solitaria postura -no firmar el "Acta de Sucesión» en el que se declaran ilegítimos los descendientes de Catalina y legítimos los de Ana Bolena- que, irremisiblemente, le conducirá al cadalso. Una de las contestaciones más contundentes de Moro a su hija es ésta:

""Vaya, Margaret", contestó mi padre, "jel papel que representas, no lo representas muy mal! Pero, Margaret, primero, y por lo que se refiere a las leyes del país, aunque todo hombre nacido y viviendo en él está obligado a obedecerlas en cada caso bajo pena de castigo temporal, $y$ en muchos casos bajo pena de disgustar a Dios también, aun así ningún hombre está obligado a jurar que toda ley está bien hecha, ni tampoco está obligado bajo pena de disgustar a Dios, a poner en práctica tal punto de la ley si fuera de verdad injusto" $1{ }^{5}$.

Pero como indicamos al principio, aunque la idea sea antigua, su regulación como derecho fundamental tiene pocas décadas. Aproxi-

2 Ver Sófocles, Ayax, Antígona, Edipo Rey, Navarra, Biblioteca Básica Salvat, 1982, p. 91.

3 En 1966 Fred Zinnemann estrena A Man for All Seasons, la versión castellana de esta película, que recibió cinco Oscars, es Un hombre para la eternidad.

4 "Los "escritos de la Torre" de Sir Tomás Moro son una obra maestra. Entre el 17 de abril de 1534 y el 6 de julio de 1535, el célebre humanista inglés, encarcelado en la famosa Torre-prisión de Londres, escribió varios cientos de hojas que forman uno de !os más conmovedores testimonios de la fidelidad de un ser humano a su conciencia y a sus prineipios". Ver Alvaro de Silva, "Introducción" en Tomás Moro, Un hombre solo. Cartas desde la Torre, Madrid, Rialp, 1990, p. 13.

5 Ver Tomás Moro, ob. cit., p. 57. 
mándonos a las cuestiones más jurídicas, lo primero que hemos de apuntar es que este tema se nos presenta problemático, entre otras razones, por la ausencia de regulación normativa alguna sobre la objeción de conciencia, salvo en el supuesto del servicio militar. Por lo demás, es un tema delicado y complejo en el que se mezclan las dimensiones más profundas del ser humano: vida, muerte, religión, libertad, conciencia, etc. Esto, de forma consciente o inconsciente, produce muchas veces análisis jurídicos viciados, es decir, se parte primero de la postura a favor o en contra que se tenga sobre la materia para, posteriormente, navegar en el ordenamiento jurídico a la búsqueda de fundamentos, apoyos $y$ argumentos para la defensa de la posición previamente adoptada. No creemos que esta forma de proceder contribuya a aclarar y perfilar tan decisiva materia. Precisamente en temas tan delicados como el aborto, la objeción de conciencia, la vocación profesional, etc., el jurista debe buscar la plasmación de la realidad del ordenamiento jurídico de la forma más objetiva posible, es decir, tratando de describir e interpretar la realidad jurídica que hay $y$ no lo que se desea que haya forzando a ésta. Son pues, estos dos puntos señalados, dos dificultades que suelen acompañar a los estudios sobre la objeción de conciencia y a su repercusión en el ámbito de la sanidad.

Nuestra Constitución española tan sólo contempla la objeción de conciencia para el caso del servicio militar. El resto de supuestos que a ésta afectan tienen que ser regulados por creación jurisprudencial y por remisión a otros artículos de la CE, principalmente el 16.1 que consagra la libertad religiosa e ideológica.

Por último, señalar que después de la objeción de conciencia al servicio militar, es la objeción de conciencia al aborto la que más se está reconociendo y, a su vez, configurando dentro de los diferentes ordenamientos jurídicos de nuestro entorno europeo ${ }^{6}$.

\section{ELEMENTOS CONSTITUTIVOS DE LA OBJECIÓN DE CONCIENCIA}

Hay muchas definiciones sobre la objeción de conciencia. Sin embargo, más que definirla nos interesa apuntar aquellos elementos que la constituyen y que nos indican si nos encontramos o no ante un

- Ver J. Oliver Araujo, La objeción de conciencia al servicio militar, Madrid, Civitas, 1993, p. 46. 
supuesto de objeción de conciencia. Siguiendo a Gómez Sánchez habría cuatro elementos a tener en cuenta:

"1. La existencia de una norma jurídica, con un contenido que pueda afectar a las creencias religiosas o morales de los individuos, cuyo cumplimiento no puede obviarse sin incurrir en sanción.

2. La existencia igualmente de un dictado inequívoco de la conciencia individual opuesto al mandato jurídico.

3. La ausencia en el Ordenamiento jurídico de normas que permitan diluir el conflicto entre la norma y la conciencia individual.

4. La manifestación del propio sujeto sobre el conflicto surgido entre la norma y su conciencian?.

En resumen: norma, conciencia, conflicto entre ambas y manifestación del mismo por el afectado. La falta de cualquiera de los cuatro elementos constitutivos supondría que no nos encontramos frente a un supuesto de objeción de conciencia. De ahí, que en muchos casos, se plantea erróneamente el problema de la objeción de conciencia (la manifestación del conflicto no la realiza el afectado sino familiares o amigos, el sujeto no tiene la madurez necesaria para poder hablar de conciencia, etc.).

\section{SUJETOS DE LA OBJECIÓN DE CONCIENCIA}

En buena lógica jurídica, no debiéramos de separar en este caso los elementos constitutivos de la objeción de conciencia de los sujetos de la misma, pues, atendiendo a los elementos $2 .^{\circ}$ y $4 .^{\circ}$ indicados, dependiendo del sujeto afectado, estaremos realmente ante un supuesto de objeción de conciencia. Por poner un ejemplo sencillo, es obvio que un niño de cuatro años no puede tener su conciencia formada plenamente, lo mismo ocurre con un adulto incapaz, se incumple, por lo tanto, el segundo elemento constitutivo.

De esta forma, como teoría general, nos podemos encontrar con los siguientes casos que iremos estudiando a lo largo del trabajo: a) paciente: adulto capaz, adulto incapaz, menor, preso, sujeto colectivo $y$

7 Ver Yolanda Gómez SÁNCHEZ: "Reflexiones jurídico-constitucionales sobre la objeción de conciencia y los tratamientos médicos", en Revista de Derecho Político, n.* 42, 1997, p. 63. 
sujeto jurídico. b) personal sanitario: funcionario, contratado laboral, médico, personal auxiliar, persona jurídica (centros sanitarios).

\section{DIFERENTES SUPUESTOS DE OBJECIÓN DE CONCIENCIA}

Estudiaremos en este cuarto apartado tres diferentes supuestos de objeción de conciencia dentro del ámbito sanitario. Consideramos que, en la actualidad, son los tres casos más frecuente y de mayor polémica: la objeción de conciencia del personal sanitario, la del paciente frente a la asistencia médica obligatoria o coactiva y, por último, el más reciente supuesto de la objeción de conciencia farmacéutica.

\section{La objeción de conciencia del personal sanitario}

\section{a) Introducción}

La objeción de conciencia es un derecho fundamental que envuelve toda nuestra vida $y$, por supuesto, dentro de ella, la vida profesional, donde los conflictos no abarcan sólo a cuestiones de conciencia o jurídicos, sino también al propio trabajo, a la deontología profesional e incluso, en algunos casos, al peligro de sufrir discriminaciones en nuestro propio puesto de trabajo, con todo lo que ello implica.

Las motivaciones que fundamentan la objeción de conciencia al aborto suelen basarse en la moral, en los usos deontológicos ${ }^{8}$ o en las creencias religiosas, si las tuviere, del sujeto activo. Estas motivaciones son incompatibles, y aquí nace el conflicto, con el cumplimiento del deber profesional establecido en una norma vigente. En este caso concreto, el derecho que el ordenamiento jurídico en vigor ${ }^{9}$ reconoce a la gestante a interrumpir su embarazo en los tres supuestos legalmente contemplados. En este delicado conflicto de derechos, la única vía jurídica razonable es la ponderación o coexistencia de los mismos -siempre que ambos logren la consideración de derechos fundamentales- en

8 «El personal sanitario por tradición multisecular ha establecido en sus códigos deontológicos la no inclusión del procedimiento abortivo entre los actos exigidos por la lex artis ad hoc". Ver María Jesús Garcia Torres: "La objeción de conciencia al aborto" en Derecho y Opinión, 1993 (1), p. 45.

9 Infra, apartado d) «regulación jurídica». 
lo que ya es reiterada jurisprudencia del Tribunal Constitucional en otros casos semejantes.

\section{b) Sujetos}

Al hablar de objeción de conciencia del personal sanitario, básicamente nos estamos refiriendo al supuesto de la objeción de conciencia al aborto. Se da cuando el médico, anestesistas, personal de enfermería, auxiliares de clínica, estudiantes en prácticas, etc. ${ }^{10}$, expresan su negativa a realizar o colaborar directa o indirectamente en la ejecución de prácticas abortivas. La objeción de conciencia no cabe lógicamente en personal que no sea sanitario, "no podrán alegarla el personal de dirección y administración, de mantenimiento (por ejemplo, en la RF Alemana llegó a plantearse por los encargados del mantenimiento del sistema de aire acondicionado) y otros servicios auxiliares (cocina, farmacia, etc.) ${ }^{11}$. Dejando a un lado el supuesto del servicio auxiliar de farmacia ${ }^{12}$ que es complicado $y$, por lo tanto, requiere un tratamiento más específico ${ }^{13}$; sí "parece inapropiado admitir la objeción de conciencia de los sujetos que no tienen ninguna participación en la práctica del embarazo. En caso contrario habría que admitir, por ejemplo, que la recepcionista, telefonista, o los camilleros alegaran sus reservas de conciencia, hipótesis a todas luces desproporcionada para su función en la división del trabajo hospitalarion ${ }^{14}$.

10 «Ante todo, es pacífico que este tipo de objeción de conciencia no ha de considerarse privativo de los médicos, sino que corresponde también a Ayudantes Técnicos Sanitarios y a cualquier otro personal sanitario susceptible de actuar en prácticas abortivas". Ver Alfonso RuIZ MIGUEL, El aborto: problemas constitucionales, Cuadernos y Debates, n. ${ }^{\circ}$ 25, Centro de Estudios Constitucionales, Madrid, 1990, p. 109-110.

11 Ver Carlos María Romeo Casabona: "La objeción de conciencia en la praxis médica" en Libertad ideológica y derecho a no ser discriminado, Madrid, Consejo General del Poder Judicial, 1996, p. 93.

Sin embargo, últimamente el supuesto de la objeción de conciencia de los farmacéuticos respecto del despacho de fármacos abortivos se está considerando seriamente.

12 Ver Paloma Villareal Suárez de Cepeda: "La objeción de conciencia del farmacéutico en relación con los métodos anticonceptivos y el aborto" en Derecho y Opinión, 1993 (1), p. 123-134. Más extensamente, José LóPEz GUZMÁN, Objeción de conciencia farmacéutica, Barcelona, Ediciones Internacionales Universitarias, 1997.

13 Infra, apartado IV.3.

14 Ver Miguel Ángel García Herrera, La objeción de conciencia en materia de aborto, Vitoria-Gasteiz, Servicio Central de Publicaciones del Gobierno Vasco, 1991, p. 121. Se sobreentiende que el autor quiere decir: en la práctica ude la interrupción” del embarazo. 
No creemos, en otro orden de cosas, que la distinción entre médico o personal sanitario privado y médico o personal sanitario público (funcionario) tenga la relevancia suficiente para obviar un derecho fundamental regulado en la Constitución. Es pues el artículo 16.1 CE limite del artículo 27.1 del Estatuto Jurídico del Personal Médico de la Seguridad Social ${ }^{15}$. Más adelante veremos la trascendencia que esta distinción puede tener en el terreno de las consecuencias jurídicas por la aplicación del derecho a la objeción de conciencia por parte del personal sanitario ${ }^{16}$.

Se plantea también el delicado problema de saber si una persona jurídica tiene derecho a la objeción de conciencia. Pensemos, por ejemplo, en el frecuente supuesto de que un hospital o clínica alegen este derecho frente al deseo de la gestante de interrumpir su embarazo.

Como anteriormente apuntamos ${ }^{17}$, uno de los requisitos constitutivos de la objeción de conciencia es la oposición que nace al mandato jurídico desde la conciencia individual. Es pues para ello imprescindible una conciencia individual, atributo que obviamente no se puede encontrar en una persona jurídica ${ }^{18}$. No cabe pues admitir las objeciones de conciencia institucionales. Ni de centros públicos, suceso extraño, ni de centros privados; a mayor abundamiento en este último caso pues, "de acuerdo con la normativa vigente, basta con no solicitar la autorización administrativa para mantenerse fuera de la red de centros abortistas" ${ }^{19}$. Sin embargo, la cuestión no es pacífica. La jurisprudencia constitucional ha evolucionado en el reconocimiento de derechos subjetivos (honor e intimidad) a personas jurídicas. Navarro-

15 Este Estatuto se aprobó por Decreto 3160/1966, de 23 de diciembre. Su artículo 27 apartado 1 contempla como obligaciones generales de los médicos la de «prestar personalmente sus servicios profesionales a las personas protegidas que tengan a su cargo, cuando para ello fueran requeridos por los propios interesados, por otros facultativos de la Seguridad Social o por la Inspección de Servicios Sanitarios, así como la personal dedicación a la función asistencial que les corresponda".

16 Infra, apartado IV.1.g).

17 Supra, apartado II.

18 Ver, en este sentido, Yolanda Gómez Sánchez, ob. cit., p. 74; apunta además esta autora la negativa del Tribunal Constitucional a "admitir ni siquiera como coadyuvante a una confesión religiosa (Unión de Iglesias Cristianas Adventistas del Séptimo Día) en un caso de objeción de conciencian, según ATC 578/1984.

19 Ver Miguel Ángel García Herrera, La objeción de conciencia en materia de aborto, ob. cit., p. 121.

De la misma opinión en este punto, desde posiciones muy distantes en el resto, ver Dolores Voltas BaRó, "Objeción de conciencia" en Cuadernos de Bioética, n. ${ }^{\circ}$, abril-junio 1990, p. 43. 
Valls apunta que "precisamente la libertad ideológica o religiosa tiene uno de sus campos de proyección en torno a las entidades o sociedades, como sucede con la enseñanza. Por consiguiente, la objeción de conciencia también puede ser planteada por centros sanitarios ${ }^{20}$. Ruiz Miguel, que también sostienen una postura positiva, utiliza el siguiente argumento, "el artículo 16.1 de la Constitución garantiza expresamente tales libertades no sólo a los individuos, sino también a "las comunidades". Este último término, además, debe entenderse en su sentido más amplio, si se tiene en cuenta que nuestro Tribunal Constitucional aplica el principio de que los derechos fundamentales son predicables también de las personas jurídicas en la medida que su naturaleza lo consienta, según parece ocurrir en el caso de los centros sanitarios ${ }^{21}$. Dos precisiones al respecto: 1. El término comunidades que menciona el artículo 16.1 CE más que entenderse como persona jurídica, se comprende como conjunto de individuos; obviamente, no es lógico reconocer la libertad religiosa a un individuo y negársela a tres que formen una comunidad, pero insisto -por ser un punto crucial- lo esencial del término comunidad es el ser precisamente un conjunto de individuos que comparten unas creencias $y$ que pueden tener una conciencia común que, en última instancia, refleja sus conciencias individuales compartidas. Sus diferentes naturalezas individuales compartidas o comunes, en cuanto a sus creencias religiosas, consienten que puedan tener ese derecho a la libertad religiosa ${ }^{22}$. Esto nos lleva di-

20 Ctdo. en Carlos Maria Romeo Casabona, ob. cit., p. 94. En la misma línea, y con apoyo en la jurisprudencia del Tribunal Constitucional, Alfonso RUIz MIGUEL, EI aborto: problemas constitucionales, ob. cit., p. 111-112.

En contra, Guillermo Escobar Roca, La objeción de conciencia en la Constitución española, Madrid, Centro de Estudios Constitucionales, 1993, p. 382: "La negación en todo caso de la titularidad del derecho a objetar al aborto por parte de las personas jurídicas nos parece, en definitiva, el único modo de impedir no sólo la desnaturalización de la figura de la objeción de conciencia, sino, sobre todo, el riesgo latente para la propia libertad de decisión de los individuos encuadrados en las personas colectivas".

21 Ver Alfonso RuIz MigUeL, El aborto: problemas constitucionales, ob. cit., p. 112.

22 Por lo demás, no se infiere de suyo, como supone implícitamente Ruiz Miguel, que el reconocimiento expreso a las comunidades de la libertad ideológica, religiosa y de culto del artículo $16.1 \mathrm{CE}$ implique que las personas jurídicas tienen derecho a la objeción de conciencia. No debemos olvidar que la incorporación de la objeción de conciencia al 16.1 es por vía jurisprudencial, es decir, el constituyente al establecer el término "comunidades» no pensaba, como es evidente pues sino lo habría incluido expresamente, en la objeción de conciencia. Además, creemos haber demostrado suficientemente la no equiparación de lo que es una comunidad ideológica o religiosa con lo que es un centro sanitario. 
rectamente a la segunda precisión; 2. Manteniendo el último argumento utilizado por Ruiz Miguel "los derechos fundamentales son predicables también de las personas jurídicas en la medida que su naturaleza lo consienta", creemos, a diferencia de lo defendido por él, que no es el caso de los centros sanitarios, sencillamente porque un centro sanitario es imposible que puede tener una conciencia individual.

No se puede obviar la posición relevante que en la interrupción de la gravidez desempeña el médico, no sólo a éste le corresponde la dirección en la realización del aborto, sino que también es quien conforme a la legislación vigente, debe analizar los supuestos de hecho que se le plantean y discernir si están dentro de los tres casos que regula la ley ${ }^{23}$. A este respecto pues, resulta lógico tener presente la postura y opinión de este colectivo profesional, a fin de buscar puntos de equilibrio entre su posicionamiento y el derecho que el actual ordenamiento jurídico reconoce a la gestante que desea interrumpir su embarazo.

\section{c) Perspectiva profesional}

Necesaria referencia debemos hacer, aunque carezcan de relevancia jurídica, a los diversos Códigos deontológicos de algunas de las distintas profesiones que pertenecen al ámbito sanitario. El Código de Ética y Deontología Médica de la Organización Médica Colegial de España afirma en su artículo 27:

«1. Es conforme a la Deontología que el médico, por razón de sus convicciones éticas o científicas, se abstenga de intervenir en la práctica del aborto [...]. Informará sin demora de las razones de su abstención, ofreciendo en su caso el tratamiento oportuno al problema por el que se le consultó. Y siempre respetará la libertad de las personas interesadas en buscar la opinión de otros médicos.

23 «La redacción del art. 417 bis del Código Penal atribuye al médico una relevancia considerable en el proceso abortivo. Es el especialista al que corresponde efectuar la intervención como culminación de una serie de actuaciones encaminadas a dotar de garantías, como reclamaba el Tribunal Constitucional, la interrupción del embarazo. El médico practica el aborto pero lo efectúa después de que se ha emitido un dictamen por otro colega en el que consta la necesidad de la intervención para evitar un grave peligro para la vida o la salud física o psíquica de la embarazada. Asimismo el riesgo de nacimiento de un feto con graves taras físicas o psíquicas debe ser dictaminado por dos especialistas del centro o establecimiento sanitario, público o privado, acreditado al efecto, distintos al director o ejecutor de la interrupción del embarazo". Ver Miguel Ángel Garcia Herrera, ob. cit., p. 96. 
2. El médico no debe estar condicionado por acciones u omisiones ajenas a su propia libertad a declararse objetor de conciencia. Los Colegios de Médicos le prestarán, en todo caso, el asesoramiento y la ayuda necesarios ${ }^{24}$.

En términos semejantes se manifiesta el Código Deontológico de la Enfermería española ${ }^{25}$ al señalar en su artículo 22 que:

«de conformidad en lo dispuesto en el art. 16.1 de la Constitución Española, la Enfermera/o tiene, en el ejercicio de su profesión, el derecho a la objeción de conciencia, que deberá ser debidamente explicitado ante cada caso concreto. El Consejo General y los Colegios velarán para que ninguna/o Enfermera/o pueda sufrir discriminación o perjuicio a causa del uso de ese derechon.

En relación con el inicio de la vida humana, tomando información que aporta Navarro-Valls ${ }^{26}$, debemos apuntar la declaración del Consejo de Colegios Oficiales Médicos de España que mantiene la existencia de la vida desde el momento de la concepción. La Real Academia de Medicina sostiene una postura idéntica.

En el panorama internacional se sigue una línea de opinión similar a la descrita en España. Los documentos y textos son múltiples.

24 Parecidos, aunque más imprecisos, son los Códigos deontológicos de los países de nuestro entorno.

El Código de Deontología de Francia, aprobado el 17 de enero de 1975, establece: "un médico no puede prescribir ni practicar aborto salvo en los casos autorizados por la ley $y$ en las condiciones impuestas por ella. A pesar de lo dispuesto en la ley, el médico tendrá siempre la libertad de negarse al aborto".

El Código de Deontología alemán de 20 de junio de 1970 es más vago y difuso; se expresa en estos términos: "La profesión médica exige que el médico cumpla con su misión en conciencia y según lo establecido por la tradición médica».

El artículo 57, b) del Código de Deontología italiano estipula: «si el médico, por razón de sus condiciones, considera que no debe provocarse el aborto en ningún caso, deberá proceder a los cuidados más urgentes y puede confiar su enfermo a un colegan.

Por último, están el artículo 32 y 87 del Código de Deontología de Bélgica que declaran, respectivamente: «libremente escogido o no, el médico sólo tomará las decisiones que le dicten su ciencia y su conciencia. [...] El médico puede negarse, debido a sus convicciones, a practicar la interrupción del embarazo". Ver Juan Antonio SagaRdoY BENGOECHEA: "La objeción de conciencia en el aborto y la rescisión del contrato de trabajo" en Ciencias humanas y Sociedad, Madrid, Fundación "José Luis Oriol-Catalina de Urquijon, 1993, p. 498-499.

${ }^{25}$ Aprobado por resolución n. $32 / 89$ del Pleno del Consejo General de Colegios de Diplomados de Enfermería.

${ }^{26}$ Ctdo., Miguel Ángel García Herrera, ob. cit., p. 75. 
Destacaremos los siguientes: 1. El Código Internacional de Ética Médi$\mathrm{ca}^{27}$ defiende la obligación de los profesionales de la medicina de "preservar la vida humana desde el momento de la concepción"; 2. La Carta Médico Social de Nuremberg ${ }^{28}$ afirma sin ambages: "la vida humana, desde su origen, y la persona humana, en su integridad material y espiritual, deben ser objeto de un respeto total"; 3. La Carta de Médicos Asalariados ${ }^{29}$ establece en su punto primero -que define al médico asalariado-, que el contrato de trabajo debe "garantizar al médico una independencia plena en el ejercicio de su profesión y, por tanto, establecerá las garantías de hecho y de derecho que le permitan cumplir su misión dentro del respeto a los imperativos de su conciencia y a las reglas científicas, técnicas o deontológicas de la medicina»; 4 . La Carta de los Médicos de Trabajo de la $\mathrm{CEE}^{30}$ defiende igualmente la necesidad de garantizar al médico la "completa independencia técnica y moral en relación con el patrono [...]. El médico de empresa (e igualmente el de los organismos de Seguridad Social) debe tener independencia total en el ejercicio de su profesión, comprometido tan sólo ante su conciencia médican; 5. El Congreso Médico Mundial de Oslo de $1970^{31}$ proclama el derecho de los médicos a negarse a aconsejar o ejecutar un aborto si su conciencia se lo prohíbe; dice así: "si el médico considera que sus convicciones no le permiten recomendar o ejecutar un aborto, puede ser revelado al mismo tiempo que asegure la continuidad de la asistencia médica por otro colega calificado» ${ }^{32} ; 6$. La resolución de 25 de junio de 1970 de la AMA (American Medical Association) propugna que "a ningún hospital, médico o personal sanitario se le puede obligar a realizar actos contrarios a sus principios morales" y, por último; 7. El Código Deontológico aprobado por la Federación de las Órdenes médres en 1949.

27 Adoptado en la III Asamblea de la Asociación Médica Mundial, en Lon-

28 Adoptada por el Comité Permanente de médicos de la CEE en julio de 1967.

29 Aprobada en la reunión de Bruselas de 7 de junio de 1968. En el preámbulo de la misma se indica que "la independencia profesional es un principio fundamental de la actividad médica asalariada y debe ser obligatoriamente garantizada en particular por respeto a la libertad médica de decisión y de prescripción".

30 Adoptada en noviembre de 1968 en Bruselas.

31 Cuya Declaración final actualmente se ha refundido en el Código sobre Aborto Terapéutico aprobado por la Asociación Mundial de Médicos, de la que España es socio de pleno derecho.

32 Ver, en relación con estas citas de Organismos internacionales, Juan Antonio Sagardor Bengoechea: «La objeción de conciencia en el aborto y la rescisión del contrato de trabajo", ob. cit., p. 497-498. 
dicas señala que la actividad médica se debe orientar a "la prevención y cura de las enfermedades, a la mitigación del dolor, a la defensa de la vida desde su concepción, en el respeto de la vida humanan.

\section{d) Regulación jurídica}

En contraste ${ }^{33}$ con nuestro entorno más cercano (Francia, Italia, Reino Unido, Portugal, Alemania, Estados Unidos ${ }^{34}$, etc.), en España no tenemos una ley que regule la objeción de conciencia al aborto. La Ley Orgánica 9/1985, de 5 de julio, que en buena lógica debiera de haber contemplado esta cuestión, nada apunta al respecto, y no por falta de oportunidades, pues tanto el Grupo Comunista como el Popular presentaron sendas proposiciones ${ }^{35}$ que abordaban la objeción de conciencia al aborto. Tampoco la Ley 14/1986, de 25 de abril, General de Sanidad, contempla la objeción de conciencia de los profesionales sanitarios aunque, en marcado contraste, sí lo hace minuciosamente en el caso de los pacientes. Parece apreciarse por parte del Legislador español una verdadera aversión a regular la objeción de conciencia de los profesionales de la sanidad en materia de aborto pues, ocasiones no le han faltado. Si algún día llega tal regulación, conforme al artículo 81.1 CE debiera adoptar forma de ley orgánica, pues afectaría al desarrollo de un derecho fundamental (art. 16.1 CE); por lo demás, sería recomendable que afrontase las siguientes cuestiones: «personas que podrían acogerse a la objeción de conciencia, actos incluidos en la objeción, procedimiento de su alegación y revocación explícita o implícita y medidas organizativas para suplir al objetor ${ }^{36}$.

Ante este vacío legal, el Tribunal Constitucional ha buscado suplir con sus sentencias «el silencio parlamentario y proporcionar la co-

33 «En la práctica totalidad de los países en que se ha producido alguna forma de despenalización del aborto, ha venido acompañada de un tratamiento legal de la objeción de conciencia, con la única excepción de Suecian. Ver María Jesús García Torres, ob. cit., p. 45.

34 Sobre la objeción de conciencia en Estados Unidos ver Rafael Palomino, Las objeciones de conciencia, Madrid, Montecorvo, 1994.

35 Proposición de Ley del Grupo Popular del Congreso sobre objeción de conciencia al aborto presentada el 3 de mayo de 1985. El Grupo Parlamentario Comunista lo ha intentado varias veces, presentó una Proposición de Ley el 17 de junio de 1981, reiterada por el Grupo Mixto el 17 de abril de 1985, finalmente como Grupo Parlamentario de Izquierda Unida-Iniciativa per Catalunya, el 28 de marzo de 1990.

36 Ver Carlos María Romeo Casabona: "La objeción de conciencia en..., ob. cit., p. 106. 
bertura jurídica que el legislador ha negado, hasta ahora, a la conciencia individual en materia de interrupción de la gravidez» ${ }^{37}$.

Básicamente son tres las sentencias del Tribunal Constitucional que afectan a esta cuestión: SSTC 15/1982, de 23 de abril; 53/1985, de 11 de abril y; 160/1987, de 27 de octubre. Y como ocurre con demasiada frecuencia, en ésta ${ }^{38} y$ en otras materias, no encontramos una posición coherente en las distintas sentencias del Tribunal ${ }^{39}$.

La primera Sentencia, de abril de 1982, se decanta con claridad a favor del reconocimiento y protección de la objeción de conciencia. Expone en su fundamento jurídico sexto:

"Por otra parte, tanto la doctrina como el derecho comparado afirman la conexión entre la objeción de conciencia y la libertad de conciencia. Para la doctrina, la objeción de conciencia constituye una especificación de la libertad de conciencia, la cual supone no sólo el derecho a formar libremente la propia conciencia, sino también a obrar de modo conforme a los imperativos de la misma. En la Ley Fundamental de Bonn, el derecho a la objeción de conciencia se reconoce en el mismo artículo que la libertad de conciencia y asimismo en la Resolución 337, de 1967, de la Asamblea Consultiva del Consejo de Europa se afirma de manera expresa que el reconocimiento de la objeción de conciencia deriva lógicamente de los derechos fundamentales del individuo garantizados en el artículo 9 de la Convención Europea de Derechos Humanos, que obliga a los Estados miembros a respetar las libertades individuales de conciencia y religión.

$Y$, puesto que la libertad de conciencia es una concreción de la libertad ideológica, que nuestra Constitución reconoce en el articulo 16, puede afirmarse que la objeción de conciencia es un derecho reconocido explícita e implícitamente en la ordenación constitucional españolas.

El Tribunal Constitucional no duda en esta primera sentencia en incluir la objeción de conciencia bajo el amparo del derecho a la liber-

37 Ver Miguel Ángel García Herrera, ob. cit., p. 97.

38 En la objeción de conciencia a tratamientos médicos, es decir, en la objeción de conciencia por parte del paciente, volvemos a encontrar en la jurisprudencia constitucional posiciones incoherentes con lo mantenido por él mismo. Ver Amelia Ariza Robles: "La objeción de conciencia a tratamientos médicos en la jurisprudencia del Tribunal Constitucional" en Boletín de la Facultad de Derecho, UNED, n. ${ }^{\circ} 8-9,1995$, p. 117-124.

39 Ver Alfonso RUIz MIGUEL: «Una jurisprudencia constitucional pendular» en El aborto: problemas constitucionales, ob. cit., p. 105-109. 
tad ideológica y de conciencia que regula el artículo 16.1 CE. Sin embargo, algunos autores ${ }^{40}$, incluso dos votos particulares ${ }^{41}$, criticaban por entonces la excesiva amplitud y escasa precisión de esta sentencia sobre la objeción de conciencia; solicitando pues del Alto Tribunal, una mayor concreción.

En cualquier caso, esta sentencia sitúa a la objeción de conciencia dentro de los derechos fundamentales de máxima protección, es decir, los incluidos en la Sección $1{ }^{a}$, Capítulo $2 .^{\circ}$, del Título $1 .^{\circ}$. Igual posicionamiento mantendrá en la siguiente sentencia.

La conocida Sentencia de 11 de abril de 1985, resuelve y aprecia parcialmente el recurso previo de inconstitucionalidad que se presenta contra el proyecto de Ley Orgánica de reforma del artículo 417 bis del Código Penal. Por su relevancia y trascendencia, reproducimos por entero el fundamento jurídico 14 y último de esta Sentencia, destacando las partes que consideramos de mayor interés para nuestro tema:

"Finalmente, los recurrentes alegan que el proyecto no contiene previsión alguna sobre las consecuencias que la norma origina en otros ámbitos jurídicos, aludiendo en concreto a la objeción de conciencia, al procedimiento a través del cual pueda prestar el consentimiento la mujer menor de edad o sometida a tutela y a la inclusión del aborto dentro del régimen de la Seguridad Social.

Al Tribunal no se le oculta la especial relevancia de estas cuestiones, como también la de todas aquellas derivadas del derecho de la mujer a disponer de la necesaria información, no sólo de carácter médico -lo que constituye un requisito del consentimiento válido-, sino también de índole social, en relación con la decisión que ha de adoptar.

Pero tales cuestiones, aunque su regulación pueda revestir singular interés, son ajenas al enjuiciamiento de la constitucionalidad del proyecto, que debe circunscribirse a la norma penal impugnada, de conformidad con lo dispuesto en el artículo 79 de la LOTC.

No obstante, cabe señalar, por lo que se refiere al derecho a la objeción de conciencia, que existe y puede ser ejercido con independencia de que se haya dictado o no tal regulación. La objeción de conciencia forma parte del contenido del derecho fundamental a la libertad ideológica y religiosa reconocido en el artículo 16.1 de la

40 Ver Alfonso Ruiz Miguel: "Sobre la fundamentación de la objeción de conciencia" en Anuario de Derechos Humanos, n. ${ }^{\circ} 4,1986-87$, p. 399-421.

${ }^{41}$ En concreto, el voto particular de los magistrados Latorre y Díez de Velasco, número $6 .^{\circ}$. 
Constitución y, como ha indicado este Tribunal en diversas ocasiones, la Constitución es directamente aplicable, especialmente en materia de derechos fundamentales.

$Y$ en cuanto a la forma de prestar consentimiento la menor $o$ incapacitada, podrá aplicarse la regulación establecida por el derecho privado, sin perjuicio de que el legislador pueda valorar si la normativa existente es la adecuada desde la perspectiva de la norma penal cuestionada".

Son dos los puntos que debemos resaltar: 1. Reconocimiento por parte del Tribunal del importante vacío legal que existe sobre la objeción de conciencia al aborto y; 2 . Que a pesar de ese vacío legal, puede ser ejercido el derecho a la objeción de conciencia al formar parte del contenido del artículo 16.1 CE.

Esta línea jurisprudencial experimenta un giro importante con la STC 160/1987, de 27 de octubre ${ }^{42}$, en la que va a defender una tesis más restrictiva de la objeción de conciencia en su fundamento jurídico tercero:

"Se trata de un derecho constitucional reconocido por la Norma suprema en su art. 30.2, protegido, sí, por el recurso de amparo (art. 53.2), pero cuya relación con el art. 16 (libertad ideológica) no autoriza ni permite calificarlo como fundamental. [...] Constituyen en ese sentido, una excepción al cumplimiento de un deber general, solamente permitida por el art. 30.2 en cuanto que sin ese reconocimiento constitucional no podría ejercerse el derecho, ni siquiera al amparo del de libertad ideológica o de conciencia (art. 16 C.E.) que, por sí mismo, no sería suficiente para liberar a los ciudadanos de deberes constitucionales".

Algunos autores sostienen que el reconocimiento restrictivo de la objeción de conciencia puede ser fruto del temor a las consecuencias de una aceptación amplia de la objeción de conciencia para el funcionamiento del Estado ${ }^{43}$. No dejando de ser una visión a considerar, creemos que la forma en que podemos comenzar a resolver esta aparente incoherencia del Tribunal Constitucional es afirmando dos princi-

42 De ese mismo día, y de igual línea jurisprudencial es la STC 161/1987. Sobre ambas sentencias, ver Manuel MARTínez SOSPEDRA: "Constitución española y objeción de conciencia (Acerca de las SSTC 160 y 161/87, de 27 de octubre)", Revista General de Derecho, n. 523 (abril), 1988, p. 1751-1774.

43 Ver J. Oliver Arujo, La objeción de conciencia..., ob. cit., p. 33. 
pios: 1. Existen diferentes supuestos de objeción de conciencia y, 2. Según qué supuesto, habrá que otorgarle su adecuado encuadramiento en el ordenamiento constitucional ${ }^{44}$.

Respecto del primer principio no se presentan muchas dificultades para admitirlo. La objeción de conciencia se puede aplicar al servicio militar, posiblemente el caso más conocido y el único expresamente regulado en nuestro Texto Fundamental, pero también se ha planteado en otras situaciones: al jurado ${ }^{45}$, a la contribución fiscal ${ }^{46}$, a las mesas electorales ${ }^{47}$, a tratamientos médicos, al aborto, a sistemas de aseguración obligatoria $^{48}$, en el ámbito educativo ${ }^{49}$, al juramento ${ }^{50}$, etc.

En relación con el segundo principio, debemos partir del hecho de que la objeción de conciencia es la negativa -nacida de una convicción moral, ideológica o religiosa- a cumplir una norma determinada. Sin embargo, y esto es lo relevante, no es lo mismo que:

1. La norma determinada sea un deber constitucional: supuesto del servicio militar (art. 30.1 CE) o del sostenimiento del gasto público (art. 31.1 CE);

2. La propia Constitución contemple una excepción a ese deber constitucional: sí existe en el caso del servicio militar (art. $30.2 \mathrm{CE}$ ), no se da en el supuesto de la contribución al sostenimiento del gasto público u objeción de conciencia fiscal, lo que hace este caso difícilmente viable en nuestro ordenamiento constitucional;

44 Ver Yolanda Gómez SÁnchez, ob. cit., p. 68-71.

45 Ver Alfonso Ruiz Miguel: "La objeción de conciencia, en general y en deberes cívicos" en Libertad ideológica y derecho a no ser discriminado, Cuadernos de Derecho Judicial, "La objeción de conciencia al jurado", p. 32-38, Madrid, Consejo General del Poder Judicial, 1996; Rafael NaVAaro-VALls y Javier Martínez-Torrón, Las objeciones de conciencia en el Derecho español y comparado, Madrid, McGraw-Hill, 1997, "La objeción de conciencia al jurado", p. 173-196.

46 Ibídem, "La objeción de conciencia fiscal", p. 81-96.

47 Ver Alfonso Ruiz Miguel: «La objeción de conciencia, en general y en deberes cívicos..., ob. cit., "La objeción de conciencia a las mesas electorales", p. 2532; Rafael NaVArRo-VAlls y Javier Martínez-Torrón, Las objeciones de conciencia en el Derecho español y comparado, ob. cit., "Objeción a deberes cívicos electorales», p. 223-228.

48 Ver Rafael Navarro-Valls y Javier Martinez-Torrón, Las objeciones de conciencia en el Derecho español y comparado..., ob. cit., p. 228-231.

49 Ibidem, p. 197-214.

50 Ver Guillermo Escobar Roca, La objeción de conciencia en la Constitución española, Madrid, Centro de Estudios Constitucionales, 1993, "La objeción al juramento", p. 424-435. 
3. La norma determinada sea un deber legal: caso del jurado en el que el deber a participar en la Administración de Justicia no lo regula el art. 125 CE sino la Ley que lo desarrolla ${ }^{51}$ y;

4. La norma a cumplir no tenga rango legal. El derecho subjetivo de la embarazada a interrumpir su embarazo está contemplado, en concreto, en los artículos 1 y 2 del Real Decreto 2409/1986, de 21 de noviembre, sobre centros sanitarios acreditados y dictámenes preceptivos para la práctica legal de la interrupción del embarazo.

En el caso que nos ocupa, la objeción de conciencia al aborto por parte del personal sanitario es claramente protegida por la STC $53 / 1985$. Las otras dos sentencias apuntadas, que tratan la objeción de conciencia al servicio militar, se encuentran en una situación distinta de objeción de conciencia pues existe un deber constitucional regulado ${ }^{52}$ en el artículo 30.1 CE que, por el contrario, no se da en el caso de la objeción de conciencia al aborto pues, "la objeción de conciencia de los médicos oponiéndose a realizar abortos no pugna con ninguna otra norma constitucional que establezca el deber de realizar este tipo de operaciones, no puede, pues, configurarse como exención de un deber constitucional inexistenten ${ }^{53}$.

Pero esto no significa que el objetor no infrinja con su no actuación un mandato normativo, si no fuera así no estaríamos ante el supuesto de objeción de conciencia, lo que queremos resaltar es que no debe recibir el mismo tratamiento jurídico la objeción que se plantea frente a un deber constitucional, que aquella que lo hace frente a un deber legal o reglamentario.

Por lo demás, el propio Tribunal Constitucional nos puede ayudar a deshacer la contradicción (o aparente contradicción, en su caso) que sus sentencias sobre el derecho a la objeción nos plantea. Es reiterada jurisprudencia constitucional que los derechos fundamentales gozan de una vis expansiva que implica que su interpretación debe encaminarse a la forma más favorable para la vigencia y eficacia de los mismos.

Todo lo señalado con anterioridad nos lleva pues a concluir lo siguiente:

51 Ley Orgánica 5/1995, de 22 de mayo, del Tribunal del Jurado.

52 Por otro lado, no debe olvidarse que la STC 15/1982 es anterior al desarrollo legislativo del artículo 30.2 CE, no ocurre así con la STC 160/1987.

53 Ver Yolanda Gómez SánCHEZ, ob. cit., p. 69. 
1. El reconocimiento constitucional que tiene el derecho a la objeción de conciencia (art. 16.1 CE) al aborto por parte del personal sanitario ${ }^{54}$.

\section{La necesidad y conveniencia de su regulación legal.}

3. Delimitar y solventar de la manera más ponderada posible la situación de conflicto que el reconocimiento de la objeción de conciencia crea pues, por definición, la objeción de conciencia como tal, siempre plantea una situación de conflicto. En la realidad que nos ocupa, la colisión se produce entre uel derecho de la madre gestante a la utilización de los mecanismos que le confiere la ley y el derecho del objetor a no ser discriminado o gravado por el hecho de su objeción» ${ }^{55}$.

Por último, al igual que hemos indicado que la objeción de conciencia del personal sanitario encuentra su apoyo normativo en el artículo $16.1 \mathrm{CE}$, algún autor sostiene además la integridad moral y el no sometimiento a un ciudadano a un trato degradante del artículo 15 $\mathrm{CE}^{56}$, tenemos que estudiar la naturaleza jurídica del derecho de la embarazada a interrumpir la gravidez. Estamos ante una cuestión compleja en la que nos podemos encontrar frente a distintas posturas:

1. Tesis defendida normalmente por posturas antiabortitas. Niegan el derecho de la embarazada al aborto como tal derecho subjetivo ${ }^{57}$.

54 «Parece muy dudoso que, con las salvedades y límites que enseguida se harán, pueda ser constitucional negar el derecho de los médicos a objetar la práctica de abortos por razones de conciencia, en aplicación de las libertades reconocidas en el artículo 16 de la Constitución. Y, en nuestro mismo ámbito de cultura, puede servir de criterio indicativo indiciativo el que legislaciones sobre interrupción voluntaria del embarazo como la francesa, la italiana o la portuguesa reconozcan con gran generosidad ese derecho". Ver Alfonso Ruiz Miguel: El aborto: problemas constitucionales, ob. cit., p. 108.

${ }_{55}$ Ver Rafael NAVARRO-VALLS: "La objeción de conciencia al aborto" en Libertad ideológica $y$ derecho a no ser discriminado, Madrid, Consejo General del Poder Judicial, 1996, p. 57.

56 Ver Juan Antonio Sagardoy Bengoechea: "La objeción de conciencia en el aborto y la rescisión del contrato de trabajon, ob. cit., p. 496.

57 J. A. Sagardoy y J. M. DEL VAlle, de forma similar, sostienen la tesis de un "precepto legal de mera tolerancia», cfr. "Aborto: objeción de conciencia y rescisión de contrato de trabajo" en J. Gafo (ed.), Dilemas éticos de la medicina actual, Madrid, Publicaciones de la Universidad Pontificia de Comillas, p. 318.

En concreto, Sagardoy sostiene que cel médico o personal sanitario que se niega a la práctica del aborto no desconoce el derecho fundamental (ni siquiera subjetivo) de un tercero; tan sólo dice no a la demanda de un particular que se acoge a un precepto legal de mera tolerancia". Ver Juan Antonio SAGARDOY BENGOECHEA: "La objeción de conciencia en el aborto y la rescisión del contrato de trabajon, ob. cit., p. 493-494. 
El argumento es el siguiente. "El hecho de que un delito esté despenalizado no obliga a cometerlo, y ni siquiera se puede decir que la ley lo permite; simplemente, no lo castiga. ¿Acaso la falta de castigo engendra un derecho en alguien, y por tanto un deber correlativo en otro? Es decir, en este caso, no existe un derecho al aborto por parte de la mujer embarazada ni un deber a practicarlo por parte del médico.

En consecuencia, el médico no tiene por qué presentar aquí recurso de objeción. Al médico no se le puede obligar por ley a practicar abortos. Le ha de bastar con exponer su criterio personal de que no considera su deber médico practicarlo, sin necesidad de más requisitos. Nada ni nadie pueden obligarle. La ley no manda y ni siquiera autoriza los abortos, simplemente no los castiga en algunos casos. Es una diferencia esencial, fundamental. No cabe hablar de "abortos legales", sino de "abortos no punibles" ${ }^{58}$. Esta posición sostendría que no es precisa la objeción de conciencia del personal sanitario pues no se da el supuesto de hecho de la objeción de conciencia, es decir, la existencia de una norma jurídica cuyo cumplimiento pueda violentar la conciencia del sujeto.

2. Existe una segunda postura que defiende que el derecho de la embarazada a interrumpir su embarazo no se articula como un deber constitucional (por ejemplo, como la defensa de España del artículo $30.1 \mathrm{CE}$ ). No niega la realidad jurídica de este derecho subjetivo, pero no le concede un reconocimiento constitucional. Su contemplación como tal tiene su cobertura inicial en el artículo 417 bis del derogado Código penal pero que, conforme a la disposición derogatoria única, 1. a), del Código Penal de $1995^{59}$, continúa en vigor. Sin embargo, el derecho subjetivo de la embarazada es fruto directo del RD 2409/1986, de 21 de noviembre, ya señalado. Este Real Decreto «convertirá aquellas conductas despenalizadas en auténticos derechos subjetivos de la embarazada, de la misma naturaleza que el resto de los derechos asistenciales, y desencadenantes, en lógica y necesaria correlación, de deberes jurídicos de los entes públicos (arts. 1 y 2 del citado RD) " ${ }^{60}$. No estamos pues, en principio, ante un derecho fundamental, tampoco frente a un deber constitucional; pero sí frente a un deber jurídico -sino no habría supuesto de hecho de la objeción de conciencia-regulado en

\footnotetext{
58 Ver Dolores Voltas Baró, ob. cit., p. 42.

59 La Ley Orgánica 10/1995, de 23 de noviembre, aprobó el nuevo Código Penal, que entró en vigor el 24 de mayo de 1996.

6o Ver Guillermo Escobar Roca, La objeción de conciencia en la Constitución española, ob. cit., p. 378.
} 
el artículo 2.1 del RD 2409/1986. De esta forma, "el deber de practicar abortos en los supuestos legales pasa a formar parte "automáticamente" (art. 2.1 del RD) del conjunto de deberes derivados de la relación laboral o funcionarial que liga al personal sanitario $y$ asimilado con la Administración sanitaria» ${ }^{61}$.

3. Una tercera postura interpretaría el derecho de la embarazada como un límite a los derechos fundamentales (en nuestro caso, al art. 16.1 CE). Este límite no nacería del reconocimiento, como derecho fundamental, del derecho de la embarazada sino que daría a éste la consideración de bien constitucionalmente protegido en virtud de la salud de la madre que encontramos en el art. 43.1 CE. La STC 43/1990 establece que los límites a los derechos fundamentales hay que enterderlos referidos «no sólo a su conexión con otros derechos constitucionales, sino también a otros bienes constitucionalmente tutelados ${ }^{62}$.

4. La cuarta tesis es generalmente defendida por posiciones proabortistas que sostienen el reconocimiento constitucional del derecho de la embarazada a interrumpir la gravidez, en base a la libertad que para toda persona consagra el artículo $17.1 \mathrm{CE}$, a la protección de la salud ${ }^{63}$ del artículo $43.1 \mathrm{CE}$, y al derecho a la dignidad de la mujer que propugna el artículo $10.1 \mathrm{CE}$.

Creemos que son la segunda y tercera tesis las que mejor reflejan la realidad de nuestro ordenamiento jurídico respecto de la cuestión. Las otras dos tesis buscan más, en nuestra modesta opinión, apoyos normativos a sus creencias ideológicas o religiosas, que una comprensión objetiva de la realidad que contempla el ordenamiento jurídico en vigor.

Dicho esto, debemos matizar que los diferentes bienes jurídicos que buscan protegerse en los tres supuestos legales para la interrupción del embarazo si pueden encontrar, alguno de ellos, apoyo en los derechos fundamentales regulados en nuestra Constitución española de 1978.

Estudiemos los tres supuestos. El aborto terapéutico puede encontrar su apoyo constitucional en el artículo 15 que garantiza el derecho a la vida y a la integridad física y moral, y en el 43.1 sobre el derecho a

61 Ibidem, p. 378-379.

62 Ctdo. en Miguel Angel García Herrera, ob. cit., p. 117.

63 La Organización Mundial de la Salud define ésta como el "estado de completo bienestar físico, mental y social y no meramente la ausencia de enfermedad o invalidez". 
la salud. Puede pues plantearse un conflicto entre estos derechos fundamentales y el del artículo 16.1 sobre la objeción de conciencia. El aborto fruto de una violación, tiene a nuestro parecer un engarce constitucional no tan claro como el supuesto anterior; sin embargo, el Tribunal Constitucional encuentra que este supuesto tiene su apoyo constitucional en los artículos 10.1, 15 y 1864. Por último, se nos antoja ciertamente dificil vislumbrar algún derecho fundamental de nuestro Texto Fundamental para dar cobertura constitucional al aborto eugenésico, tal vez, la libertad personal ${ }^{65}$ del artículo 17.1.

Resumiendo, de los tres supuestos tan sólo dos pueden plantear la lógica ponderación que, según reiterada jurisprudencia del Tribunal Constitucional, debe realizarse entre derechos fundamentales en conflicto.

Por último, un breve apunte sobre el tan falazmente polémico cuarto supuesto que con cierta periodicidad se plantea ${ }^{66}$. Decimos falaz simplemente porque, de hecho, el cuarto supuesto está funcionando en la realidad de la sociedad española desde la misma reforma de 1985 . Un dato, en este sentido, vale más que mil palabras. Señala Ruiz Miguel, "nadie que no sea extremadamente ingenuo o que, en el extremo opuesto, esté directamente interesado en la actividad de las clínicas privadas para abortos, puede creer sensatamente que, por ejemplo, los 26.069 abortos legales declarados que constan en las estadísticas de Sanidad para 1988, de los cuales se aduce la indicación terapéutica en el 98 por ciento de los casos, entren ni de lejos en las causales del artículo 417 bis ${ }^{67}$. Sin embargo, no debemos dejar de reflejar la realidad en toda su amplitud. Aunque pocos, existen médicos que han sido condenados en virtud de infringir la normativa penal y actuar al margen de los tres supuestos del artículo 417 bis. Es pues una situación de manifiesta inseguridad jurídica pues, en líneas generales se incumple claramente

64 Ver Guillermo Escobar Roca, ob. cit., p. 387.

65 En estos últimos años está prosperando en Estados Unidos la posibilidad que los padres tienen de demandar a los médicos que no advirtieron las posibles malformaciones de los fetos. El argumento utilizado es que las deficiencias del futuro hijo/a coartan la libertad de los padres. Este supuesto es conocido con el nombre de wrongful conception. Recientemente, esta teoría se ha aplicado por primera vez en España, por el Juzgado de Primera Instancia no 32 de Barcelona, en sentencia de 10 de febrero de 1999. Ver Diario Médico, miércoles, 24 de febrero de 1999, p. 7.

66 La última vez en otoño de 1998, por el Grupo parlamentario socialista en el Congreso de los Diputados. Su propuesta de ley de inclusión del cuarto supuesto no prospero por un diferencia mínima de votos.

67 Ver Alfonso Ruiz Miguel, El aborto: problemas constitucionales, ob. cit., p. 13-14. 
el ordenamiento jurídico, como antes indicamos, pero en un pequeñísimo porcentaje, sí trata de aplicarse $y$, de hecho, se aplica. Obviamente, esta situación genera un gran desconcierto e inseguridad dentro del personal sanitario que no sabe a qué atenerse. Las propuestas para superar esta situación de inseguridad juridica son, básicamente tres: a) Aplicar el ordenamiento jurídico vigente en la totalidad de los casos. Esto es, respetar el Estado de Derecho; b) No aplicarlo, como parece ser la realidad, pero hacerlo en todos los casos y; c) Normativación de la realidad, contemplar pues jurídicamente el cuarto supuesto. De las tres propuestas, la primera sería la jurídicamente correcta, pero creería una enorme cantidad de problemas al chocar frontalmente con una realidad que se viene dando desde hace más de una década. La tercera, a la luz de la experiencia de hace pocos meses, produce una profunda división en la sociedad española. Probablemente la más conveniente, y la más jurídicamente inaceptable, sería la segunda.

\section{e) Límites}

La doctrina mayoritariamente está a favor de la prevalencia del derecho a la objeción de conciencia del personal sanitario, incluso si ésta es sobrevenida ${ }^{68}$. En este sentido Ruiz Miguel sostiene que "la objeción de conciencia de los médicos y demás personal sanitario está constitucionalmente garantizada sin distinciones sobre el momento en que se puede presentar y tanto en el ámbito de la sanidad pública como en el de la privada" ${ }^{69}$. A este respecto, debemos considerar el artículo 9.2 del Real Decreto de 21 de noviembre de 1986 que indica que

68 Peces-Barba defiende la objeción sobrevenida sólo en supuestos muy particulares: «en casos excepcionales se podría aceptar que determinados tipos de personas necesitan de la experiencia práctica para que se desarrollen valores morales generales que son incapaces de comprender en abstracto, y sólo en esos casos tendría explicación la objeción sobrevenida". Ver Gregorio PeCEs-BarBa MARTiNEZ: "Desobediencia civil y objeción de conciencia" en Anuario de Derechos Humanos,.$^{\circ}$ 5, 1988-1989, p. 173. p. 115-116.

${ }_{69}$ Ver Alfonso RuIz Miguel, El aborto: problemas constitucionales, ob. cit.,

En relación a la objeción de conciencia en la sanidad pública y en la sanidad privada, la realidad demuestra que la uobjeción por razones de conciencia se plantea en España de hecho principalmente en los centros hospitalarios públicos (por ejemplo, de la Seguridad Social), pero puede tener lugar también, aunque con mucho menor intensidad, en los establecimientos privados". Ver Carlos María Romeo Casabona: "La objeción de conciencia..., ob. cit., p. 90. 
"la no realización de la práctica del aborto habrá de ser comunicada a la interesada con carácter inmediato al objeto de que pueda con el tiempo suficiente acudir a otro facultativo". Pues bien, cabe que el sujeto pueda objetar siempre y cuando quede ese "tiempo suficiente" para acudir a otro facultativo, en caso contrario, estaríamos frente a uno de los límites ya contemplados del derecho a la objeción de conciencia: los casos de urgencia vital.

Sin embargo, no estamos ante un derecho absoluto -ninguno lo es- y cabe el límite que el propio artículo $16.1 \mathrm{CE}$ recoge respecto del orden público y que en la LO 7/1980, de Libertad Religiosa ${ }^{70}$, en su articulo 3.1, se concreta en los siguientes límites: la "salvaguardia de la seguridad, de la salud y de la moralidad pública» ${ }^{71}$. Por lo tanto, decae el derecho a la objeción de conciencia del personal sanitario en estos casos apuntados, y en los de verdadera urgencia, es decir, aquellos en los que peligre gravemente la salud física o psíquica de la mujer; "en estos casos el médico tiene el deber de actuar para proteger -directa o indirectamente, según su posición en relación con el bien jurídico- la vida o la salud de la embarazada, siendo el aborto el medio -efectonecesario e inevitable para la satisfacción de aquél, partiendo siempre de la hipótesis de que en estos casos el aborto ha sido solicitado por la embarazada" ${ }^{72}$. Quizá el caso más claro y manifiesto de este supuesto sea el de los médicos de guardia, aunque en la realidad es harto improbable que pueda darse.

En la extraña hipótesis que un médico ante una urgencia vital se negará por motivos de conciencia a practicar un aborto, falleciendo la madre, "y fuera por ello procesado por un delito de homicidio por omisión, podría entrar en juego la atenuante $8^{\mathrm{a}}$ del artículo 9 del $\mathrm{CP}{ }^{73}$.

En este mismo sentido, Blanco Rodríguez aporta los siguientes datos. En el último trimestre de 1987 constan 2.325 abortos practicados en clínicas privadas de Madrid frente a 48 en hospitales públicos madrileños. En el mismo periodo de 1988 constan 2.732 abortos en clínicas privadas frente a 97 en públicas. Ver Benigno Blanco Rodríguez: "El aborto en España: ¿un inmenso fraude de ley?» en Boletín del Ilustre Colegio de Abogados de Madrid. Revista Jurídica General, n. 6 (noviembrediciembre), p. 83-84.

70 De 5 de julio, en adelante LOLR.

11 Para la interpretación de este límite, infra, apartado IV.2, a) "Los Testigos de Jehová".

72 Ver Carlos María Romeo CASABONA: "La objeción de conciencia en la praxis médica" en Libertad ideológica y derecho..., ob. cit., p. 99.

73 Ver Guillermo Escobar Roca, ob. cit., p. 387. En el Código Penal de 1995, de tener consideración como atenuante la objeción, sería en la atenuante $6^{\mathbf{a}}$ del artículo 21. 
Fuera pues de esta circunstancia extrema, es competencia de la Administración sanitaria "procurar siempre que el aborto pueda ser practicado por un médico no objetor ${ }^{74}$ para, de esta forma, evitar la situaciones de conflicto que, salvo casos extremos, pueden ser fácilmente evitables. Pero, incluso, imaginemos un caso hipotético de objeción generalizada o masiva, qué ocurriria con el derecho de la embarazada a abortar. "En estos casos, claramente imputables a una defectuosa organización sanitaria, juzgamos difícil que, desde las coordenadas constitucionales pueda obligarse a un médico-objetor a realizar la operación. No obstante, quedará a la interesada la posibilidad de demandar a la Administración por vulneración, por omisión, de su derecho fundamental lo subjetivo) a abortarn ${ }^{75}$. Incluso puede solicitar la cuantía del dinero gastado -reintegro de gastos- en una clínica privada por una prestación que conforme a derecho ${ }^{76}$ debiera de haber cubierto la Sanidad pública.

Nos restan dos cuestiones para concluir este apartado. Primera, más que apuntar otro límite, señalar la lógica veracidad que debe acompañar a la objeción de conciencia. Evidentemente ésta no cabe cuando el propio médico realiza prácticas abortivas, "es un claro fraude a la ley que no sólo no merece protección, sino que podría ser susceptible de sanciones disciplinarias por incumplimiento de los deberes correspondientes" ${ }^{77}$.

Segunda, el médico-objetor no puede, abusando en alguna medida de su posición de autoridad y superioridad, no informar a la embarazada que desea interrumpir su gravidez de las alternativas que ésta tiene ante la objeción de conciencia por él manifestada ${ }^{78}$. Negar esa in-

74 Ver Guillermo Escobar RocA, ob. cit., p. 389.

75 lbídem, p. 390.

76 A este respecto, el Real Decreto 63/1995, de 20 de enero, sobre ordenación de las prestaciones sanitarias del Sistema Nacional de Salud (BOE $10 \mathrm{de}$ febrero de 1995) contempla expresamente este supuesto en su Anexo I, apartado 3, punto 4, letra g): «[...] Interrupción voluntaria del embarazo en los supuestos a que se refiere la Ley Orgánica 9/1985, de 5 de julio".

77 Ver Alfonso Ruiz Miguel, ob. cit., p. 123.

78 El articulo 9 del Real Decreto 2409/1986, de 21 de noviembre, establece:

"Los profesionales sanitarios habrán de informar a las solicitantes sobre las consecuencias médicas, psicológicas y sociales de la prosecución del embarazo o de la interrupción del mismo, de la existencia de medidas de asistencia social y de orientación familiar que puedan ayudarle. Informarán asimismo de las exigencias o requisitos que, en su caso, son exigibles, asi como la fecha y el centro o establecimiento en que pueden practicarse.

La no realización de la práctica del aborto habrá de ser comunicada a la interesada con carácter inmediato al objeto de que pueda con el tiempo suficiente acudir a otro Facultativo». 
formación excedería los límites de la objeción de conciencia y pudiera considerarse como una infracción sanitaria ${ }^{79}$.

\section{f) Procedimiento y actividades objetables}

Otra cuestión delicada es el procedimiento por el cual el objetor manifiesta su negativa al deseo de la gestante de, conforme a derecho, interrumpir su embarazo. Como es sabido, existe un procedimiento establecido para el ejercicio de la objeción de conciencia al servicio militar que la STC $160 / 1987^{80}$ ha considerado respetuoso con el artículo 16.1 y 2 , y con el 18.1 de la Constitución española. Consideramos que partiendo de la base real de que la objeción de conciencia al aborto del personal sanitario afecta directamente al derecho de la gestante a interrumpir el embarazo, y con la única finalidad de conciliar ambos derechos sin que ninguno se vea perjudicado, es recomendable un mínimo procedimiento formal y flexible que no perjudique el derecho del objetor, pero que tampoco su ausencia pueda significar un serio deterioro de la eficacia del derecho de la embarazada al aborto en los supuestos legalmente reconocidos ${ }^{81}$.

A este respecto la legislación italiana sobre la materia puede resultar bastante ilustrativa ${ }^{82}$. El artículo 9 de la Ley de 22 de mayo 1978 contempla la objeción de conciencia del personal sanitario en los siguientes términos:

79 En este sentido, ver artículo 35 de la Ley 14/1986, de 25 de abril, General de Sanidad.

80 En concreto, su fundamento jurídico $5 . b$ ):

"La posible colisión con los derechos reconocidos en los artículos 16.2 y 18.1 desaparece por el mismo ejercicio del derecho a la objeción, que en sí lleva la renuncia del objetor a mantener en el ámbito secreto de su conciencia sus reservas ideológicas a la violencia y/o a la prestación del servicio militar, bien entendido que sin esa voluntad del objetor dirigida a extraer consecuencias jurídicas -y por tanto exteriores a su conciencia- de su objeción nadie podrá entrar en su intimidad ni obligarle a declarar sobre su ideología, religión o creencias».

81 En esta materia del procedimiento discrepan claramente las Proposiciones de Ley que sobre la materia presentaron en su día: a) el Grupo Popular (en 1985) que defiende la ausencia de procedimiento respecto del derecho a la objeción y; b) el Grupo de Izquierda Unidad-Iniciativa per Catalunya (en 1990) que establece en su artículo 11.1: «El personal sanitario, médicos, ATS y demás personal sanitario podrá formular reserva de no participación en interrupciones voluntarias del embarazo comprendidas en los artículos anteriores ante la autoridad sanitaria competente. La reserva constará en un registro creado para tales supuestos. [...]".

82 En concreto, la Ley $\mathrm{n}^{\circ}{ }^{194}$, de 22 de mayo de 1978, norme per la tutela sociale della maternità e sull'interruzione volontaria della gravidanza. 
"el personal sanitario y el que ejerce las actividades auxiliares no está obligado a participar en los procedimientos previstos en los art. 5 y 7 y en las intervenciones para la interrupción del embarazo cuando plantee objeción de conciencia, previamente declarada. La declaración del objetor debe ser comunicada al médico provincial y, en el caso del personal empleado del hospital o clínica, también al director sanitario, antes de un mes después de la entrada en vigor de la presente ley o de la obtención de la habilitación o de la asunción del puesto en un ente obligado a proporcionar prestaciones dirigidas a la interrupción del embarazo, o de la estipulación de un convenio con entes asistenciales que comporte la ejecución de tales prestaciones.

La objeción puede siempre ser revocada o venir planteada también fuera de los términos previstos en el párrafo anterior, pero en tal caso la declaración produce efecto después de un mes de su presentación al médico provincial».

Probablemente estemos ante la regulación más rigurosa y precisa del Derecho comparado de nuestro entorno ${ }^{83}$. Logra conciliar de forma ciertamente satisfactoria los derechos en conflicto ${ }^{84}$. Al objetor se le exige una previa declaración expresa, pero no se establece ningún procedimiento de verificación de la misma. La declaración se dirige a las instituciones sanitarias superiores. Se admite la objeción de conciencia sobrevenida, pero se la somete al plazo de un mes para conciliar ambos derechos, el del objetor y el de la embarazada. Además, el legislador italiano pone como límite a la objeción de conciencia los casos de extrema necesidad $y$, deslinda dentro del objeto de la objeción de conciencia las actividades principales de las secundarias; por tanto, quedan excluidas de la objeción de conciencia las fases preparatorias y posoperatorias. Esta cuestión parece no ser excesivamente polémica, siendo aceptada la exclusión de esas fases incluso por quienes están en contra de las prácticas abortivas ${ }^{85}$. Sin embargo, compartimos

83 Ver Miguel Ángel García Herrera, ob. cit., p. 90.

84 Favorable a la solución que propone la legislación italiana es García Arán. Ver Mercedes Garcia ARÁN: "La objeción de conciencia del médico en relación a la interrupción del embarazo" en El aborto, 1982, p. 128-129.

85 "Tanto en la asistencia anterior al aborto como en la posterior a la intervención, no se suscita ningún problema de conciencia si no existía un compromiso previo (ni expreso ni tácito) y ha surgido inesperadamente. En este caso, no cabría incluirlos en el ámbito de la objeción. Si tras la intervención surgen complicaciones, aún inmediatas, el administrar los cuidados necesarios para salvar la vida o para la salud de la mujer, son obligados para el personal sanitario, en ausencia involuntaria del equipo que realizó el aborto; de lo contrario, se entraría en 
con Escobar Roca que la división de la actividad del médico en fases preparatorias y ulteriores no es la más útil para abordar el problema. Propone este autor la división en actividades:

1. Administrativas y similares. En las que salvo para el caso del médico o persona que dirige el hospital o la unidad, no cabe el supuesto de la objeción ${ }^{86}$.

2. Médicas. Dentro de éstas sí se establece una diferencia cronológica entre el antes, durante y después de la intervención quirúrgica. Cabe la objeción en la fase preparatoria o de emisión de dictámenes preceptivos que la norma exige; evidentemente en la fase de la intervención $y$, es prácticamente unánime que una vez practicado el aborto, no podemos encontrarnos ya ante un supuesto de hecho objeción de conciencia ${ }^{87}$.

Como hemos podido observar, la diferencia entre fases preparatorias y posteriores nos resulta insuficiente, teniendo que precisar si en estas fases la actividad es meramente administrativa o, por el contrario, médica.

En España, algún autor se ha manifestado partidario de un procedimiento similar al expuesto, aunque no en la cuestión del plazo previo de un mes. Así, Sagardoy señala que «determinar un plazo de preaviso en cuanto a la negativa no creo que sea la solución. [...] debe adoptarse a priori, esto es, desde el nacimiento mismo del contrato de trabajo, una reserva de conciencia donde se advierta la imposibilidad moral del médico de acceder a la demanda de quienes quieran abortar. Ello elimina también las dudas que al respecto pueda tener el beneficiario de la Seguridad Social en la elección de quien la atienda, evitando así malentendidos» ${ }^{88}$.

\section{g) Consecuencias del ejercicio de la objeción}

Es competencia de la Administración subsanar las dificultades que puedan nacer para el derecho de la gestante cuando el objetor ejer-

un caso de negación de asistencia». Ver Dolores Voltas Baró: "Objeción de conciencia” en ob. cit., p. 44.

86 En sentido contrario, Ruiz Miguel defiende que: «parece razonable y protegible la objeción de quien argumenta que su actividad, aunque indirecta y no definitiva, es un medio necesario para el aborto que su conciencia no le permite emprender. Desde la recepción administrativa...). Ver Alfonso RuIz MigueL, ob. cit., p. 117.

87 Ver Guillermo Escobar Roca, ob. cit., p. 383-385; Alfonso Ruiz MigueL, ob. cit., p. 116-117.

88 Ver Juan Antonio Sagardoy Bengoechea: "La objeción de conciencia en el aborto y la rescisión del contrato de trabajon, ob. cit., p. 500. 
ce su derecho a la objeción de conciencia; "en este sentido podemos recordar las posibilidades de selección ofrecidas por la legislación noruega, la obligación impuesta en la normativa francesa de crear unidades de aborto cuando el jefe de servicio se niega a asumir la responsabilidad del servicio, o la movilidad de personal contemplada en la regulación italiana» ${ }^{89}$.

En nuestra ordenamiento jurídico podemos encontrar apoyo legal para solventar estas situaciones en el segundo párrafo del artículo 87 de la Ley 14/1986, de 25 de abril, General de Sanidad, que contempla que:

«El personal podrá ser cambiado de puesto por necesidades imperativas de la organización sanitaria, con respecto de todas las condiciones laborales y económicas dentro del Area de Salud".

Este párrafo no deja de ser coherente con los principios generales que la Ley regula en el capítulo primero del título primero, concretamente, con aquéllos contemplados en el artículo 7:

"Los servicios sanitarios, así como los administrativos, económicos y cualesquiera otros que sean precisos para el funcionamiento del Sistema de Salud, adecuarán su organización y funcionamiento a los principios de eficacia, celeridad, economía y flexibilidad ${ }^{90}$.

Por otro lado, desde la posición del personal sanitario que objeta, no puede éste sufrir por el ejercicio de su derecho ningún tipo de discriminación, perjuicio profesional u otros «medios sutiles, como pueden ser las represalias de tipo socio-profesional ${ }^{91}$. En este punto, los auxiliares sanitarios son los sujetos más vulnerables, pues su relación profesional está sometida a la normativa de las relaciones jurídicas contractuales. Es pues el despido un elemento verdaderamente disuasorio para el posible objetor. Para evitar esta situación, que atacaría frontalmente el derecho contemplado en el artículo $16.1 \mathrm{CE}$, "cualquier despido por este motivo habría que calificarlo al menos de improcedente -o incluso nulosiguiendo el criterio del Tribunal Constitucional (2-III-85) ante despidos que afectaban a la libertad de expresión ideológica de un profesorn ${ }^{92}$.

$89 \quad$ lbídem, p. 126.

so El principio de eficacia que debe regir la actuación de la Administración Pública está constitucionalizado en el artículo 103.1.

91 Ver Dolores Voltas Baró, ob. cit., p. 41.

92 Ibídem, p. 43. 
Cualquier tipo de discriminación, por razones de conciencia o por otros motivos, es contraria al artículo 14 de la Norma Fundamental; tanto si afecta a médicos, como a auxiliares, como a los propios centros que no participan de las prácticas abortivas. En este sentido, no pueden admitirse los despidos, traslados, cambios de jefatura e incluso la negativa de la Seguridad Social a realizar convenios con los centros, cuando detrás de estas actuaciones hay un intento de discriminar a quienes ejercen su legítimo derecho a la objeción de conciencia o simplemente se niegan a realizar prácticas abortivas (caso de los centros) ${ }^{93}$.

Por lo demás, sí es preciso atender la inclusión o no en el contrato del deber de practicar abortos, pues «quien libre y voluntariamente acepta el deber laboral de practicar abortos no pierde por ello la titularidad del derecho a objetar, sino que aquella circunstancia hará necesaria después una ponderación diferente que, como veremos, se materializará en la distinta calificación del despido" ${ }^{94}$.

Vamos a estudiar con algún detenimiento esta cuestión de la negativa a practicar abortos por parte del personal sanitario y la posible rescisión del contrato de trabajo ${ }^{95}$. Hay que partir, dentro de la relación laboral, del deber de obediencia del trabajador respecto de las órdenes empresariales. Tal imperativo está regulado en el Estatuto de los Trabajadores: «El trabajador estará obligado a realizar el trabajo convenido bajo la dirección del empresario o persona en quien éste delegue ${ }^{96}$. Sin embargo, este principio, obviamente, no es de carácter absoluto, estando sometido a límites ${ }^{97}$, que podrían concretarse, según ha venido interpretando reiterada jurisprudencia, en los siguientes puntos: 1 . Las órdenes deben estar dentro del terreno de la legalidad; 2. Están limitadas a los trabajos o actividades convenidas y; 3 . No pueden afectar a la moralidad del trabajador ${ }^{98}$.

A la luz de estas consideraciones previas, se puede determinar que los médicos contratados por organismos privados (clínicas priva-

93 Ibídem.

94 Ver Guillermo Escobar Roca, ob. cit., p. 381.

95 Tema éste analizado principalmente por SAGARdoY BengOECHEA: "La objeción de conciencia en el aborto y la rescisión del contrato de trabajo", ob. cit., p. $493-500$.

96 Ver artículo 20.1 de la Ley $8 / 1980$, de 10 de marzo, del Estatuto de los Trabajadores.

97 La STS de 10 de diciembre de 1976 sostiene que uel deber de obediencia no puede ser entendido en forma tan absoluta que imponga el cumplimiento de cuantas órdenes e instrucciones se reciban en relación con el trabajo".

98 En este sentido, consultar STS de 18 de diciembre de 1962 (A/5027). 
das) en cuyo contrato se especifique que las clínicas se dedican a estas prácticas abortivas, es evidente que están obligados a cumplir lo voluntariamente pactado o convenido, tal y como indicaba el Estatuto de los Trabajadores ${ }^{99}$. Obviamente, no ocurre lo mismo en el caso contrario, es decir, cuando nada se dijo o se estableció en el contrato. En este último caso, no cabe el deber de obediencia. Las consecuencias jurídicas en caso de negativa por parte del médico a la práctica del aborto en los dos supuestos vistos son bien diferentes. En el primer caso cabe el despido (despido pues procedente) por negativa al deber de obediencia, mientras que en el segundo no (despido improcedente). Los mismos criterios pueden aplicarse para el supuesto de que el médico sea funcionario. Habrá que estar a lo que establezca o regule el Estatuto funcionarial y si contempla o no la obligación de realizar abortos ${ }^{100}$.

Un caso no excesivamente diferente en su resolución es el que se da, dentro de los centros sanitarios públicos, cuando un enfermero o personal auxiliar sanitario plantea la objeción de conciencia frente a su superior jerárquico dentro de la escala de la función pública, es decir, normalmente el médico que esté dirigiendo el equipo y que sí está a favor de las prácticas abortivas. Al igual que vivimos para los supuestos laborales, el deber de obediencia funcional al superior jerárquico dentro de la función pública no es absoluto, siendo la objeción de conciencia del artículo 16.1 de nuestra Constitución uno de sus límites. La única excepción que cabría, aparte de las genéricas ya apuntadas de la objeción de conciencia (casos urgentes, etc.), seria que estuviera expresamente estipulado dentro de las funciones propias de ese puesto de trabajo.

\section{La objeción de conciencia del paciente y la asistencia médica obligatoria o coactiva}

\section{a) Los Testigos de Jehová}

Esta cuestión fue tratada en el Auto del Tribunal Constitucional 369/84, de 20 de junio, cuya doctrina uparece señalar que la objeción

99 Concretamente, el citado artículo 20.1.

100 Ver Guillermo Escobar RocA, ob. cit., p. 390-391.

En este sentido ya apuntamos el artículo 27.1 del Estatuto Jurídico del Personal Médico de la Seguridad Social que establece las obligaciones generales de los médicos, supra, apartado IV.1.b). Expresamente nada se dice de la práctica de abortos. Habrá pues que atender a lo señalado en el ya estudiado Real Decreto 2409/1986, de 21 de noviembre sobre centros sanitarios acreditados. 
de conciencia a este tipo de tratamientos no está protegida en nuestro Derecho» ${ }^{10}$. Sobre la base del artículo 3 de la Ley Orgánica de Libertad Religiosa $7 / 80$, de 5 de julio, existe una autorización legítima para la actuación judicial, pues el derecho fundamental a la libertad religiosa del artículo $16.1 \mathrm{CE}$ tiene como límite la salud de las personas ${ }^{102}$. La LOLR dice literalmente en su artículo 3.1:

«El ejercicio de los derechos dimanantes de la libertad religiosa y de culto tiene como único límite la protección del derecho de los demás al ejercicio de sus libertades públicas y derechos fundamentales, así como la salvaguardia de la seguridad, de la salud y de la moralidad pública, elementos constitutivos del orden público protegido por la Ley en el ámbito de una sociedad democrática».

Debemos analizar con detenimiento este artículo pues resulta clave para encauzar la cuestión que estamos estudiando. Hay que tener presente que los derechos fundamentales y las libertades públicas contemplados en nuestra Constitución no pueden agotar su regulación en la propia Norma Fundamental, para su desarrolio normativo pues, hemos de atender a sus respectivas normas con rango de Ley Orgánica, según el artículo 81.1 de la CE. En el supuesto que nos ocupa, la libertad religiosa, sí existe esa norma de desarrollo, como ya hemos indicado.

El citado artículo 3.1 de la LOLR regula el ejercicio de la libertad religiosa y de culto, contemplando que tan sólo existe un único límite al ejercicio de esta libertad, el expuesto por el propio artículo 3.1. Por lo tanto, queda claro que no hay más límites a este derecho que los que vamos a indicar. Básicamente son dos, y por lo demás, se repiten en todos los derechos fundamentales:

1. El ejercicio de los derechos fundamentales y libertades públicas de los otros; por todos es sabido que ningún derecho fundamental es absoluto y entre ellos se limitan y;

2. La salvaguardia de la seguridad, salud y moralidad pública, como elementos constitutivos del orden público ${ }^{103}$. Límite que está contemplado por el mismo artículo 16.1 de la CE.

101 Ver Amelia ARIZA Robles: «La objeción de conciencia a tratamientos médicos en la jurisprudencia del Tribunal Constitucional. Las hemostransfusiones y los testigos de Jehová. La asistencia médica obligatoria en el caso de huelga de hambre" en Boletín de la Facultad de Derecho, n. 8-9, UNED, Madrid, 1995, p. 118.

102 Ver fundamento jurídico $3 .^{\circ}$ del Auto citado.

103 Ruiz Miguel apunta que la fórmula empleada por el Legislador está «repleta de conceptos jurídicos indeterminados». Ver Alfonso RuIz MIGUEL, El aborto: problemas constitucionales, ob. cit., p. 105. 
El segundo límite no se refiere a la seguridad, salud o moralidad particular o privada de la persona. Es claro que se refiere a los elementos constitutivos del orden público, a la seguridad de todos, a la moralidad pública y a la salud pública. Por lo tanto, no se refiere, por ejemplo, a la salud individual sino al peligro para la salud pública, se busca pues proteger a la comunidad para el mantenimiento del orden público. Se pretende evitar crisis sanitarias, tales como epidemias y situaciones de contaminación graves, pudiendo aplicar las medidas establecidas en las normas para la lucha contra las enfermedades infecciosas ${ }^{104}$.

La correcta interpretación del límite contemplado en el artículo 3.1 de la LOLR, en coherencia con el término orden público por él utilizado, se sustenta en que la seguridad de la comunidad es un bien jurídico superior a la libertad religiosa del individuo, pero quede claro que es la salud de la comunidad o cuando ésta está en peligro, no la salud de un individuo, sobre todo si es éste el que desea hacer uso de su libertad religiosa frente a su salud. No creemos que este último caso se pueda encuadrar dentro del artículo 3.1 de la LOLR. Insistimos, el bien jurídicamente protegido en el límite de la salud pública es la salud de la comunidad, no la de un individuo aislado. Siguiendo con este mismo artículo que establece que los límites a la libertad religiosa son exclusivamente los allí contemplados, no consideramos que la salud individual del sujeto que ejerce la libertad religiosa quede encuadrado dentro del concepto de orden público al que se refiere el artículo 16.1 de la CE y el 3.1 de la LOLR. En caso pues de conflicto, conforme al artículo 16.1 de la CE y el artículo 3.1 de la LOLR que lo desarrolla, prevalece el derecho a la libertad religiosa del individuo.

\section{b) Los presos y la huelga de hambre}

Para este caso hemos de atender las SSTC 120/90, de 27 de junio y 137/90, de 19 de julio. Ambas sentencias resuelven sendos recursos de amparo interpuestos por presos del GRAPO que están en huelga de hambre, poniendo pues, en riesgo su propia vida. Aquí los motivos no son religiosos sino la búsqueda de concentración de presos del GRAPO en un mismo establecimiento. Dice el Tribunal Constitucional:

"Una cosa es la decisión de quien asume el riesgo de morir en un acto de voluntad que solo a él afecta (en cuyo caso podría soste-

104 Ver artículos 4.b) y 12.1 de la Ley Orgánica 4/1981, de 1 de junio, de los Estados de Alarma, Excepción y Sitio. 
nerse la ilicitud de la asistencia médica obligatoria o de cualquier otro impedimento a la realización de esa voluntad) y cosa bien distinta es la decisión de quienes, hallándose en el seno de una relación especial penitenciaria, arriesgan su vida con el fin de conseguir que la Administración deje de ejercer o ejerza de distinta forma potestades que le confiere el ordenamiento jurídico, pues en este caso la negativa a recibir asistencia médica sitúa al Estado [...] contemplar pasivamente la muerte de personas que están bajo su custodia y cuya vida está obligado a preservar y proteger ${ }^{105}$.

Es contradictorio el Tribunal Constitucional pues su jurisprudencia no varía para el primer supuesto que contempla respecto del que resuelve. Así, cuando afirma que "una cosa es la decisión de quien asume el riesgo de morir en un acto de voluntad que solo a él afecta" como si fuera una caso que exigiera un tratamiento jurídico por su parte distinto del de los presos del GRAPO, vemos que en la realidad no es así, negándose igualmente la objeción de conciencia frente a la asistencia médica obligatoria, como ya apuntamos al analizar el ATC 369/84 referente a los Testigos de Jehová.

En el fundamento jurídico octavo de la STC 120/90 hay un párrafo clarificador que viene a introducir el artículo $15 \mathrm{CE}$ en el supuesto que estamos analizando. Aprecia el Tribunal que este artículo:

"garantiza el derecho a la integridad física y moral, mediante el cual se protege la inviolabilidad de la persona, no sólo contra ataques dirigidos a lesionar su cuerpo o espíritu, sino también contra toda clase de intervención en esos bienes que carezca del consentimiento del titular. Por ello este derecho constitucional resultará afectado cuando se imponga a una persona asistencia médica en contra de su voluntad que puede venir determinada por los demás variados móviles y no sólo por el de morir y, por consiguiente, esa asistencia médica coactiva constituirá limitación vulneradora del derecho fundamental, a no ser que tenga justificación constitucional». cional:

Varios puntos nos aclara esta Sentencia del Tribunal Constitu-

1. La asistencia médica coactiva (contra la voluntad del sujeto adulto y capaz) vulnera la integridad física regulada en el artículo $15 \mathrm{CE}$;

2. Es indiferente el móvil que configure la voluntad; 
3. La única excepción que cabe para que la asistencia médica coactiva no vulnere el artículo $15 \mathrm{CE}$ es que haya una justificación constitucional, no legal. Es decir, que el derecho fundamental del artículo 15 CE encuentre su límite en otro derecho fundamental.

Nada tenemos que decir respecto de los puntos $1 .^{\circ}$ y $3 .^{\circ}$, sí discrepamos del segundo. La objeción de conciencia, para ser tal, debe, según vimos, basarse en motivos de conciencia (religiosa, ideológica, moral, etc.) no en cuestiones de oportunidad política. En esta ocasión no estamos realmente ante un problema de conciencia sino ante otro caso de naturaleza distinta.

Por lo demás, para el caso que nos ocupa es esclarecedor el artículo 25.2 de la CE: «[...] El condenado a pena de prisión que estuviere cumpliendo la misma gozará de los derechos fundamentales de este Capítulo, a excepción de los que se vean expresamente limitados por el contenido del fallo condenatorio, el sentido de la pena y la ley penitenciaria [...]». Es pues la ley penitenciaria, y lo que ella contemple, un límite constitucionalmente regulado respecto de los derechos fundamentales del preso. Y no sólo al artículo $15 \mathrm{CE}$ en cuanto a la integridad física, sino que también es procedente traer a colación la libertad física salvaguardada en el artículo $17.1 \mathrm{CE}^{106}$.

La cuestión clave la expone Hervada ${ }^{107}$ al manifestar lo incoherente que es admitir el derecho a la libertad religiosa del artículo 16.1 CE y no admitir las consecuencias que se derivan del mismo. En otras palabras, si admitimos la libertad religiosa de los Testigos de Jehová y de su credo, no podemos dejar de admitir las consecuencias de sus actos en conciencia, en última instancia, si no admitimos su objeción de conciencia no admitimos la libertad para su credo religioso, es decir, la libertad religiosa del artículo $16.1 \mathrm{CE}$.

La protección de la salud del ciudadano por parte de los poderes públicos es, en primer lugar, un derecho cuyo titular es el ciudadano, no el Estado y, en segundo lugar, es un derecho del ciudadano, no un deber.

Deontológicamente, los médicos siempre han de respetar las convicciones religiosas, ideológicas o morales de sus pacientes adultos y capaces. Así lo regula el artículo 24 del Código de Deontología médi-

toe Así lo hace el Magistrado D. Jesús Leguina Villa en su voto particular a la STC 120/30.

107 Ver J. HeRVADA: "Libertad de conciencia y error sobre la moralidad de una terapéutica" en Persona y Derecho, n. ${ }^{\circ} 11,1984$, p. 13-53. 
ca de la Organización médica colegial de España. La única excepción que se puede plantear es la existencia de terceros que dependan del paciente, hijos menores, etc.

\section{La objeción de conciencia farmacéutica ${ }^{108}$}

Es ésta una de las objeciones de conciencia que ha sido planteada y estudiada más recientemente. Esto viene a demostrar que el tema de la objeción de conciencia es una cuestión abierta que paulatinamente puede irse expandiendo a diferentes supuestos. Concretamente en España, en estos últimos años, este tipo de objeción de conciencia está planteándose cada vez más. Prueba de ello, pero también de que estamos al inicio del proceso, es el frustrado proyecto de un Código Deontológico Farmacéutico ${ }^{109}$. En su artículo 52 establecia: «el farmacéutico podrá negarse, en conciencia, a dispensar cualquier tipo de fármaco o utensilio, si tiene indicios racionales de que será utilizado para atentar contra la salud de alguna persona o la propia vida humanan. Esta ausencia priva a la profesión de una siempre deseable mayor homogeneidad de actuación profesional al disponer de un referente claro y expreso como debe ser un Código Deontológico, además de las consecuencias favorables que un Código normalmente tiene para la defensa del correcto ejercicio de la profesión y de los derechos propios de la misma. Asi, por ejemplo, la existencia de un artículo como el 52 antes citado, ayudaría ostensiblemente a la mejor defensa y protección del derecho a la objeción de conciencia del farmacéutico. Baste, a este respecto, atender al caso de los médicos o de las/os enfermeras/os.

\section{a) Cuestiones previas}

Antes de entrar en las diversas situaciones que se nos pueden plantear dentro de la abjeción de conciencia de los farmacéuticos, hay que apuntar dos diferencias que nos serán de gran utilidad para el correcto desarrollo de la cuestión.

108 Que tratemos la objción de conciencia farmacéutica aparte, no implica que no consideremos al farmacéutico como personal sanitario, todo lo contrario, la importancia de su función invita a un tratamiento diferenciado.

109 "La Real Academia de Farmacia elaboró, en 1991, un Código Deontológico Farmacéutico, pero no fue promulgado posteriormente por el Consejo General de Colegios Oficiales de Farmacéuticos y por ello quedó totalmente olvidado". Ver José LOPEZ GuZMÁN, ob. cit., p. 89 , nota n. 30. 
Primera, distinguir entre el medicamento y el producto sanitario. No es un tema baladí, como veremos. La Ley 25/1990, de 20 de diciembre, del Medicamento, establece en su artículo octavo una serie de definiciones ${ }^{110}$ de interés para la materia. En su apartado primero define qué es medicamento:

"toda sustancia medicinal y sus asociaciones o combinaciones destinadas a su utilización en las personas o en los animales que se presente dotada de propiedades para prevenir, diagnosticar, tratar, aliviar, o curar enfermedades o dolencias o para afectar a funciones corporales $o$ al estado mental. También se consideran medicamentos las sustancias medicinales o sus combinaciones que puedan ser administrados a personas o animales con cualquiera de estos fines, aunque se ofrezcan sin explícita referencia a ellos».

Por otro lado, se regula en el apartado duodécimo la definición de producto sanitario:

"cualquier instrumento, dispositivo, equipo, material u otro artículo, incluidos los accesorios y programas lógicos que intervengan en su buen funcionamiento, destinados por el fabricante a ser utilizados en seres humanos, sólo o en combinación con otros, con los fines de:

- Diagnóstico, prevención, control, tratamiento o alivio de una enfermedad o lesión.

- Investigación, sustitución o modificación de la anatomía o de un proceso fisiológico.

- Regulación de una concepción.

Cuya acción principal no se alcance por medios farmacológicos, químicos o inmunológicos, ni por el metabolismo, pero a cuya función puedan concurrir tales medios".

Pues bien, si ponemos en relación estos dos artículos con el 3.1 de la misma Ley que señala lo siguiente:

"Los laboratorios, importadores, mayoristas, oficinas de farmacia, servicios de farmacia de hospitales, centros de salud y demás

110 Concretamente trece: medicamento, sustancia medicinal, excipiente, materia prima, forma galénica o forma farmacéutica, especialidad farmacéutica, medicamento prefabricado, producto intermedio, fórmula magistral, preparado o fórmula oficinal, producto en fase de investigación clínica, producto sanitario y, producto de higiene personal. 
estructuras de atención a la salud están obligados a suministrar o a dispensar los medicamentos que se les soliciten en las condiciones legales y reglamentariamente establecidas ${ }^{111}$.

Se puede colegir sin dificultad que, a sensu contrario, no existe la obligación legal de dispensar productos sanitarios ${ }^{112}$. Por tanto, la objeción de conciencia sólo cabría frente a los medicamentos pues es en este caso, y no en el del producto sanitario, en el que existe una obligación legal ${ }^{113}$, supuesto de hecho necesario para encontrarnos ante un verdadero caso de objeción de conciencia.

Sin embargo, la obligación de suministar o dispensar medicamentos tiene más límites que las condiciones legales y reglamentariamente establecidas que apunta el artículo 3.1 de la Ley del Medicamento. Debemos atender también al título IX de la misma Ley en el que se regula el régimen sancionador. En el artículo 108 se establecen

111 Complementario de este artículo es el 3.5 de la Ley 25/1990, de 20 de diciembre, del Medicamento, que establece:

"La custodia, conservación y dispensación de medicamentos de uso humano corresponderá:

- A las oficinas de farmacia abiertas al público legalmente autorizadas.

- A los servicios de farmacia de los hospitales, de los Centros de Salud y de las estructuras de Atención Primaria en los casos y según las condiciones que se establezcan de acuerdo con el artículo 103, número 1 de la Ley General de Sanidad".

112 Entre ellos se pueden encontrar el DIU, los preservativos, etc. A este respecto, nos advierte López Guzmán que "el farmacéutico, en relación con la venta del condón, no se ve sometido a la misma presión que con el anticonceptivo, ya que el preservativo es un producto sanitario y además no se distribuye exclusivamente a través de la oficina de farmacia». Ver José LóPEZ GUZMÁN, ob. cit., p. 131.

Bien es verdad que el comprar este producto en una oficina de farmacia ofrece al usuario mayores garantías, que se nos presentan como muy necesarias, al considerar la función de disminución del riesgo -que no desaparición-que los preservativos tienen frente a la infección por VIH.

Otra cuestión que puede resultar problemática es el de las jeringuillas en el caso de su uso por drogodependientes. Este artículo de uso medicinal es muy útil para evitar el contagio del SIDA, pero también su dispensación es una forma de no afrontar el verdadero problema de fondo que es la drogadicción. Es desde luego una cuestión muy delicada para el farmacéutico que desea actuar en conciencia, pues parece que las alternativas son elegir entre Scila o Caribdis.

113 Debemos recordar, siguiendo a Folch Jou, que la dispensación puede ser de dos tipos: a) libre y de total responsabilidad para el farmacéutico v; b) regulada (exigencia de receta) y de responsabilidad compartida entre el médico que ha prescrito el medicamento y el farmacéutico que lo dispensa. Ver G. FolcH Jou, Deberes y responsabilidades del farmacéutico, Madrid, Publicaciones del Consejo General del Colegio Oficial, 1979, p. 52-53. 
las infracciones. Dentro de las consideradas graves, contempla el art. 108.2, letra b) veintiún casos. Dice el decimoquinto:

"La negativa a dispensar medicamentos sin causa justificada y la dispensación sin receta de medicamentos sometidos a esta modalidad de prescripción".

Por lo tanto, nuevamente cabe interpretar la validez de negarse a dispensar medicamentos con causa justificada, «algunos motivos que pueden justificar que se rehúse una dispensación están bastante definidos, como la negativa a facilitar una especialidad cuando la receta está fuera de plazo de vigencia, o la negativa a dispensar cuando, con razones fundadas, se duda de su validez. Se trata de cuestiones de carácter formal que no plantean ningún tipo de probleman" ${ }^{114}$. Tampoco sería excesivamente problemática la negativa a dispensar en cuestiones materiales, pero de puro sentido común; por ejemplo, no suministrar "un jarabe con glucosa a un diabético, un antibiótico a un alérgico a dicho medicamento" ${ }^{115}$.

La cuestión clave a resolver en la materia que estamos estudiando es la siguiente: ¿puede considerarse el supuesto de conciencia como causa justificada para la negativa a dispensar? Si la respuesta es afirmativa, no se plantearía el caso de la objeción de conciencia, puesto que no se daría la exigencia normativa, elementos constitutivo necesario para el supuesto de hecho de la objeción. Si, por el contrario, la contestación es negativa, entonces sí cabría la posibilidad de la objeción de conciencia frente a la exigencia normativa.

La segunda diferencia que debemos analizar es entre el aborto y la anticoncepción ${ }^{116}$. De forma sintética, podríamos afirmar que la anticoncepción impide la concepción mientras que el aborto suprime el fruto de la concepción ${ }^{117}$. En la práctica, sin embargo, no siempre la di-

114 Ver José LóPez GuZMÁN, ob. cit., p. 96.

115 lbídem.

116 Para una análisis de valoración moral de las diferencias entre aborto y anticoncepción ver Alfonso RuIz Miguel, ob. cit., p. 52-57. Afirma Ruiz Miguel que "por un lado, el valor de ese tipo de vida potencial no es idéntico al de la vida actual $y$, por otro lado, tampoco la vida potencial meramente posible merece igual valor que la ya en curso. Esta graduación en la atribución de valor sugiere, a la vez que reclama, una mayor precisión en los límites de cada una de las situaciones básicas» (p. 56-57). Personalmente creemos que la división más relevante para esta cuestión es la diferencia entre vida y no vida que, por lo demás, resulta muy clara y evidente.

117 Ver José López Guzmán, ob. cit., p. 109. 
ferencia entre los efectos de ambos es clara ${ }^{118}$. En líneas generales, los mayores problemas de conciencia no se suelen plantear en las situaciones de anticoncepción sino en los casos de aborto.

\section{b) Diferentes supuestos}

Siguiendo a López Guzmán ${ }^{19}$ podemos plantearnos seis casos: el farmacéutico de oficina de farmacia, de hospital, investigador, de industria, en la Administración y, por último, el alumno de Farmacia en estancias tuteladas.

Para el primer supuesto, el farmacéutico de oficina de farmacia, debemos analizar su derecho a la objeción de conciencia atendiendo a tres circunstancias:

1. Posibilidad de sustituir al objetor. Si está alternativa es factible, el problema desaparece, otro farmacéutico dispensa el medicamento y el objetor ejerce su derecho sin ningún tipo de perjuicio para el solicitante. En caso contrario, hay que plantearse la existencia de otra farmacia en la misma población. Sólo en el supuesto de encontrarnos en una población con menos de cuatro mil habitantes el problema se agudiza, pues no habrá más de una oficina de farmacia. En este caso, habría que considerar la siguiente circunstancia;

2. Peligro para la vida del paciente o situación de urgencia. Sólo en el supuesto de que estemos ante alguno de estos dos casos, decaería, a nuestro entender, el derecho a objetar del farmacéutico, pues habría de ceder frente a otro bien jurídico: la vida humana que, en el última instancia, es el fundamento de su objeción de conciencia.

3. Titularidad de la oficina de farmacia. No es éste un tema menor para el ejercicio del derecho a la objeción de conciencia del farmacéutico. Si éste es el titular o propietario de la farmacia no se presenta ningún problema, pues es el único responsable de sus decisiones. No ocurre así cuando el objetor no es el propietario (caso del farmacéutico regente o adjunto $\left.{ }^{120}\right)$. Si propietario y colaborador coinci-

118 Ibídem. Además, ver J. T. Noonan: "Contraception" en Encyclopedia of Bioethics, New York, The Free Press, 1978, n. 1, p. 205 y; K. M. Severyn: "Abortifacient Drugs and Devices: Medical and Moral Dilemmas" Linacre Quarterly, 1990, n. ${ }^{\circ} 57$, p. 50-67.

119 Ver José López GuzMán, ob. cit., p. 115-165.

${ }^{120}$ Contemplados en la Orden de 17 de enero de 1980, sobre Funciones y Servicios de las Oficinas de Farmacia (BOE de 1 de febrero). 
den en su postura, no hay problema, incluso si no coinciden pero el propietario respeta la decisión de su colaborador-mejor además para el cliente que verá así atendida su petición. La dificultad nacerá cuando no coinciden ambos y además el farmacéutico propietario no estima la objeción del farmacéutico regente o adjunto. En esta ocasión, la solución más beneficiosa para todos ${ }^{121}$-farmacéuticos y cliente- es la distribución de la labor de dispensación del tal forma que el farmacéutico colaborador no se viera en la coyuntura de tener que dispensar un medicamento que vaya en contra de su conciencia, asumiendo pues el farmacéutico propietario esta función.

La situación del farmacéutico de hospital no difiere en esencia de la del farmacéutico de oficina pues, a la hora de resolver un posible caso de objeción de conciencia, se atenderán circunstancias parecidas a las anteriormente apuntadas. Es decir, ante la petición de un abortivo, habrá que ver si el farmacéutico objetor puede ser sustituido por otro. En la farmacia de un hospital medianamente seria y bien organizada, ésta debe ser la coyuntura normal y habitual. En caso contrario, la objeción de conciencia del farmacéutico decaería en el supuesto de que estuviera en juego un bien jurídico superior: la vida del paciente.

El tercer supuesto es el del farmacéutico investigador. Su participación en la uinvestigación farmacológica o clínica, deberá basarse siempre en el principio ético fundamental del respeto y protección de la vida y la salud humanas" ${ }^{122}$. A la hora de experimentar con embriones humanos, a parte de tener que respetar la normativa vigente al respecto ${ }^{123}$, puede plantear el farmacéutico investigador su derecho a la objeción de conciencia en el caso de que en el contrato que le une con el laboratorio no se especificaran este tipos de experimentos o investigaciones con embriones humanos. El mismo criterio se seguirá para el farmacéutico de industria que tenga que fabricar o elaborar productos abortivos, que era el cuarto supuesto a analizar. En ambos casos pues, laboratorio o industria, debemos estar a lo que se especifique en el contrato laboral del farmacéutico. Así, si se llegará al caso del despido, sería procedente si expresamente constaba en el contrato la práctica que el farmacéutico objeta, en caso contrario, el despido sería improcedente.

121 Reconocemos que esta propuesta, aunque sensata y acorde con el ordenamiento jurídico (art. 16.1 CE), posiblemente se aleje del día a día de la relación farmacéutico titular-farmacéutico regente o adjunto.

122 Ver José López GUZMÁN, ob. cit., p. 155.

${ }^{123}$ Ley $42 / 1988$, de 28 de diciembre, sobre donación y utilización de embriones y fetos humanos o de sus células, tejidos u órganos. 
Respecto del farmacéutico que trabaja en la Administración, hemos de considerar el segundo párrafo del artículo 87 de la Ley General de Sanidad de 1986:

«El personal podrá ser cambiado de puesto por necesidades imperativas de la organización sanitaria, con respeto de todas las condiciones laborales y económicas dentro del Area de Salud".

Así pues, y a la luz de este artículo, lo normal es que la Administración respete, siempre que pueda ${ }^{124}$, la objeción de conciencia de un funcionario pues, ser funcionario y pertenecer a un poder público, no implica no respetar la Constitución, tal y como se establece con claridad en el artículo 9.1 de la misma. Por lo tanto, el artículo 16.1 de la Norma Fundamental que consagra la objeción de conciencia, es eficaz tanto para un funcionario como para un no funcionario.

Queda para finalizar la situación del alumno de Farmacia que, con arreglo a los planes de estudio, tiene que realizar prácticas en una farmacia. Aquí la cuestión es clara, no estamos ante un supuesto de objeción de conciencia pues no hay norma que obligue al alumno a dispensar, "el tutelado no tiene obligación directa de dispensar, ya que, en teoría, el alumno está alli para aprender, no siendo indispensable su actuación para solventar las necesidades laborales de la oficina de farmacia»" ${ }^{125}$.

124 Pues, como establece el artículo 7 de la Ley General de Sanidad de 1986: "Los servicios sanitarios [...], adecuarán su organización y funcionamiento a los principios de eficacia, celeridad, economía y flexibilidad". Tendrá la Administración sanitaria que conciliar o conjugar, en la medida de sus posibilidades, los principios que aparecen en ambos artículos, 7 y 87 . En caso contrario, habría que estudiar los bienes jurídicos en juego para decantarse por el superior.

125 Ver José López GuzMán, ob. cit., p. 165. 